\title{
Identification of potential precursors for the occurrence of Large-Scale Traveling lonospheric Disturbances in a case study during September 2017
}

\author{
Arthur Amaral Ferreira ${ }^{1,3, *}$, Claudia Borries ${ }^{1}$, Chao Xiong ${ }^{2}$, Renato Alves Borges ${ }^{3}$, Jens Mielich ${ }^{4}$, \\ and Daniel Kouba ${ }^{5}$ \\ ${ }^{1}$ Institute for Solar-Terrestrial Physics, German Aerospace Center, 17235 Neustrelitz, Germany \\ ${ }^{2}$ Helmholtz Centre Potsdam, GFZ German Research Centre for Geosciences, 14473 Potsdam, Germany \\ ${ }^{3}$ Department of Electrical Engineering, University of Brasilia, Campus Darcy Ribeiro, 70910-900 Brasília, Brazil \\ ${ }^{4}$ Leibniz Institute of Atmospheric Physics at the University of Rostock, 18556 Juliusruh, Germany \\ ${ }^{5}$ Institute of Atmospheric Physics of the Czech Academy of Sciences, 14131 Prague, Czech Republic
}

Received 2 December 2019 / Accepted 9 June 2020

\begin{abstract}
Traveling Ionospheric Disturbances (TIDs) reflect changes in the ionospheric electron density which are caused by atmospheric gravity waves. These changes in the electron density impact the functionality of different applications such as precise navigation and high-frequency geolocation. The Horizon 2020 project TechTIDE establishes a warning system for the occurrence of TIDs with the motivation to mitigate their impact on communication and navigation applications. This requires the identification of appropriate indicators for the generation of TIDs and for this purpose we investigate potential precursors for the TID occurrence. This paper presents a case study of the double main phase geomagnetic storm, starting from the night of 7th September and lasting until the end of 8th September 2017. Detrended Total Electron Content (TEC) derived from Global Navigation Satellite System (GNSS) measurements from more than 880 ground stations in Europe was used to identify the occurrence of different types of large scale traveling ionospheric disturbances (LSTIDs) propagating over the European sector. In this case study, LSTIDs were observed more frequently and with higher amplitude during periods of enhanced auroral activity, as indicated by increased electrojet index (IE) from the International Monitor for Auroral Geomagnetic Effects (IMAGE). Our investigation suggests that Joule heating due to the dissipation of Pedersen currents is the main contributor to the excitation of the observed LSTIDs. We observe that the LSTIDs are excited predominantly after strong ionospheric perturbations at high-latitudes. Ionospheric parameters including TEC gradients, the Along Arc TEC Rate (AATR) index and the Rate Of change of TEC index (ROTI) have been analysed for their suitability to serve as a precursor for LSTID occurrence in mid-latitude Europe, aiming for near real-time indication and warning of LSTID activity. The results of the presented case study suggest that the AATR index and TEC gradients are promising candidates for near real-time indication and warning of the LSTIDs occurrence in mid-latitude Europe since they have a close relation to the source mechanisms of LSTIDs during periods of increased auroral activity.
\end{abstract}

Keywords: LSTID / ROTI / TEC gradients / AATR / GIC

\section{Introduction}

Geomagnetic storms and their associated effects have been intensively investigated for decades in order to better understand the phenomena, but also to measure their impact on human technologies (Gonzales et al., 1994). These storms are closely related to ionospheric perturbations, such as significant

\footnotetext{
*Corresponding author: arthur. ferreira@dlr.de
}

enhancements of the ionospheric electrojets, positive or negative deviations of electron densities from quiet conditions, highlatitude irregularities and other effects (Prölss, 2006; Borries et al., 2015; Cherniak \& Zakharenkova, 2015). One frequently observed phenomenon during geomagnetic storms are the large scale traveling ionospheric disturbances (LSTIDs). These are wave-like structures propagating through the ionosphere and are the ionospheric signature of Atmospheric Gravity Waves (AGWs). Often, intensive thermosphere heating in the auroral 
zones is considered to generate AGWs which propagate equatorward (Prölss, 2006; Paznukhov et al., 2009). LSTIDs propagate with horizontal velocities between 400 and $1000 \mathrm{~m} / \mathrm{s}$, horizontal wavelengths greater than $1000 \mathrm{~km}$ and periods in the range of $30 \mathrm{~min}$ to $3 \mathrm{~h}$ (Hunsucker, 1982; Hocke $\&$ Schlegel, 1996). Another type of TIDs are the medium-scale TIDs (MSTIDs), which propagate with velocities between 100 and $250 \mathrm{~m} / \mathrm{s}$, periods in the range of $10 \mathrm{~min}$ to $1 \mathrm{~h}$ and wavelengths between 100 and $1000 \mathrm{~km}$ (Hunsucker, 1982; Shiokawa et al., 2009; Chum \& Podolská, 2018). Mid-latitude MSTIDs are considered to be excited by diverse mechanisms (see Kotake et al., 2006, 2007; Kelley, 2011; Otsuka et al., 2013; Chen et al., 2019) and are out of the scope of this work.

Several studies have been performed during the last decades in an attempt to explain the LSTIDs characteristics (Bowman \& Mortimer, 2011; Shimeis et al., 2015; Habarulema et al., 2016), but the mechanisms generating LSTIDs are still not fully understood. Great importance is given to Joule heating in the auroral region. Auroral electrojet activity is repeatedly discussed in relation to LSTID generation (Wilder et al., 2012; Zakharenkova et al., 2016; Borries et al., 2017). The correlation of the LSTID amplitude with the Auroral Electrojet (AE) index has been shown in Borries et al. (2009), reaching a correlation coefficient of 0.8 (95\% significant) during solar maximum period.

The EU Horizon 2020 project "Warning and Mitigation Technologies for Traveling Ionospheric Disturbances Effects" (TechTIDE) aims at designing and testing new strategies for near real-time detection and warning for occurrence of TIDs (Belehaki et al., 2019), which requires the identification of appropriate indicators for the generation of LSTIDs. Different methods to track and detect TIDs have been developed (e.g. Juan et al., 2018; Reinisch et al., 2018; Altadill et al., 2020) and used to feed the TechTIDE warning service (Belehaki et al., 2019). In this framework, we analyze in a case study the ionospheric perturbations which occur in the source region of LSTIDs, targeting the following two objectives:

1. Identification of individual ionospheric perturbation indices that can serve as precursors for the LSTIDs occurrence in the mid-latitude European region. We focus on Total Electron Content (TEC) estimates derived from Global Navigation Satellite Systems (GNSS) measurements, because they are available in near real-time. We investigate well-known parameters including TEC gradients (often analyzed with respect to threads for groundbased augmentation systems, e.g. Pradipta \& Doherty, 2015), Rate Of change of TEC Index (ROTI, Pi et al., 1997; Jacobsen, 2014), and Along Arc TEC Rate (AATR, Juan et al., 2018).

2. Discussion of ionosphere-thermosphere dynamics, that contribute to the generation of LSTIDs. Here, we study the relations to Field-Aligned Currents (FACs) and the auroral electrojets, and address auroral precipitation effects.

We chose for our case study the 7-8th September 2017 geomagnetic storm, which is a part of the intense solar and geomagnetic disturbances that started on 6th September 2017. These disturbances generated many space weather phenomena, such as, solar flares (Berdermann et al., 2018), solar radio bursts (Sato et al., 2019), and radiation storms (Mavromichalaki et al., 2018; Mishev \& Usoskin, 2018), and effects on nearEarth space, such as, plasmasphere erosion (Obana et al., 2019), high-frequency (HF) radio wave absorption and solar flare effects (Sfe, Curto et al., 2018) and ground induced currents (GIC, Dimmock et al., 2019).

\section{Data and methods}

In this section, we present the procedure used for the LSTIDs detection, the potential precursors investigated in this work (AATR, ROTI and TEC gradients), along with the measurements and indices used to support the analysis of the ionosphere-thermosphere dynamics that contributed to the excitation of LSTIDs.

\subsection{Total Electron Content (TEC)}

TEC is a parameter widely used in the studies of the nearEarth plasma environment and it provides, along with its derived products, useful information on the ionospheric behavior during geomagnetic storms (Mendillo, 2006). It is given in TEC units (TECU), with 1 TECU corresponding to $10^{16}$ electrons $/ \mathrm{m}^{2}$ and it is defined as the integral of the electron density $N_{\mathrm{e}}$ along the line of sight between the satellite and the receiver (Mendillo, 2006; Ciraolo et al., 2007). It can be obtained from GNSS dual-frequency measurements by combining carrierphase/code pseudoranges on two frequencies as presented in equations (1) and (2):

$$
\begin{gathered}
\mathrm{TEC}=\frac{f_{1}^{2} f_{2}^{2}}{40.3\left(f_{1}^{2}-f_{2}^{2}\right)}\left[\left(\Phi_{1}-\Phi_{2}\right)+B_{\mathrm{amb}}+\varepsilon_{\Phi_{1}-\Phi_{2}}\right], \\
\mathrm{TEC}=\frac{f_{1}^{2} f_{2}^{2}}{40.3\left(f_{1}^{2}-f_{2}^{2}\right)}\left[\left(\Psi_{2}-\Psi_{1}\right)+\varepsilon \Psi_{2}-\Psi_{1}\right]
\end{gathered}
$$

where $\Phi$ and $\Psi$ are the carrier-phase and code pseudoranges, respectively. Their subscripts refer to the signals measured on frequencies $f_{1}$ and $f_{2}, B_{\mathrm{amb}}$ is the carrier-phase ambiguity, $\varepsilon_{\Phi_{1}-\Phi_{2}}$ and $\varepsilon_{\Psi_{2}-\Psi_{1}}$ correspond to noises (e.g. thermal noise). For simplicity, other terms such as inter-frequency biases and multipath effects (Hoque \& Jakowski, 2012) are not included here.

In this work, the data used for LSTIDs detection are the preprocessed GNSS TEC provided by the MIT Haystack Observatory, available at the CEDAR Madrigal database (http://cedar. openmadrigal.org/). For the period under investigation, the database provides GNSS measurements from more than 880 stations over the European region, as presented in Figure 1.

\subsection{LSTIDs detection}

In order to detect the LSTIDs the slant TEC (sTEC) is first converted into a vertical expression vTEC and the vTEC trend is removed afterwards. The sTEC at an elevation angle $\varepsilon$ is converted into an equivalent vertical TEC value according to equation (3), as described in Jakowski (1996):

$$
\mathrm{vTEC}=M(\varepsilon) \text { sTEC, }
$$

where $M(\varepsilon)$ is the slant factor that projects the slant to vertical TEC in a thin-shell model of the ionosphere and it is given by 

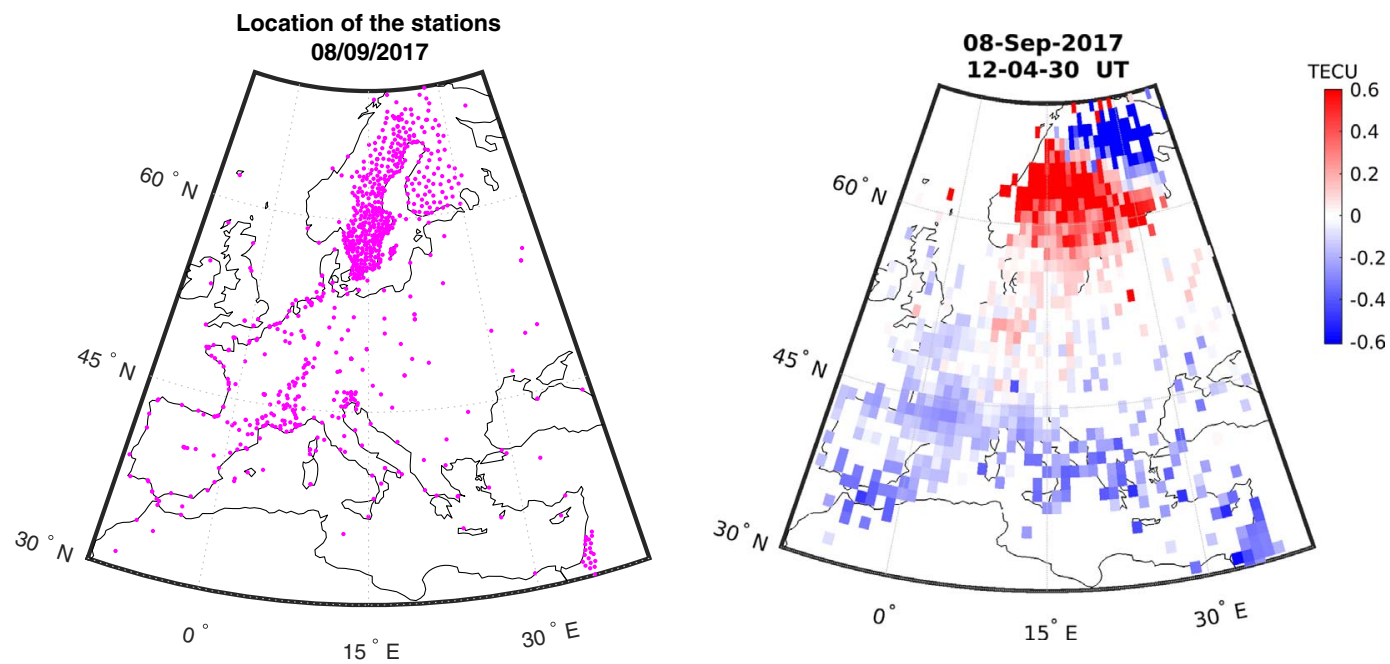

Fig. 1. Distribution of the GNSS stations provided by the CEDAR Madrigal database for the European sector (left); two-dimensional map of the detrended TEC over the European region (right).

$$
M(\varepsilon)=\sqrt{1-\left(\frac{R_{\mathrm{e}} \cos \varepsilon}{R_{\mathrm{e}}+h_{\mathrm{i}}}\right)^{2}} .
$$

The geo-reference of the resulting vTEC is the piercing point of the ray path in the ionosphere approximated as a thin-layer at the height $h_{\mathrm{i}}=350 \mathrm{~km} . R_{\mathrm{e}}=6378 \mathrm{~km}$ is the Earth radius. The accuracy of this mapping procedure is affected by the elevation angle, in such a way that it decreases with decreasing elevation (Borries et al., 2009). Therefore, a cut-off elevation angle of $30^{\circ}$ was chosen in order to reduce this mapping error. For the detrending of vTEC, an one-hour moving average window is applied (Tsugawa et al., 2004; Borries et al., 2009; Figueiredo et al., 2017), as follows:

$$
\operatorname{dTEC}(t)=\operatorname{vTEC}(t)-\overline{\operatorname{vTEC}}(t \pm 30 \mathrm{~min}) .
$$

This is done for all receiver-satellite links within a 1-minute interval. As pointed out in Zhang et al. (2019) different lengths of sliding window for TEC detrending can facilitate the detection of perturbations with different spatial and temporal scales. Previous studies indicated that the 1 hour window provides a good detection of disturbances in the temporal range of LSTIDs (e.g. Tsugawa et al., 2004; Borries et al., 2009; Cherniak \& Zakharenkova, 2015). Therefore, in this study we applied an one-hour sliding window to detect the disturbances. Nevertheless, it is important to highlight that LSTIDs perturbations with longer periods $(>1 \mathrm{~h})$ can still be detected, but with reduced amplitudes.

The detrended TEC is then mapped into a grid of $1^{\circ}$ latitude $\times 1^{\circ}$ longitude to enable a 2D visualization of the ionospheric disturbance. An example map of the detrended TEC over Europe is shown in Figure 1.

\subsection{The AATR index}

The Along Arc TEC Rate (AATR) is an indicator for regional disturbed periods in the ionosphere that can affect the GNSS applications. As shown in Juan et al. (2018), large AATR values are reached in mid-latitudes during strong geomagnetic storm, indicating that this index can be sensitive to strong ionospheric storm disturbances that originate at high latitudes and expand towards the equator. This index was developed in the context of ionospheric research for the European Geostationary Navigation Overlay System (EGNOS), and it was chosen to serve as a way to measure the operational conditions for the EGNOS. Based on this index several studies have been conducted in order to improve EGNOS availability during the intervals of large AATR. In addition, this index has been used as a standard tool for joint ionospheric studies in Space Based Augmentation Systems (SBAS) by the International Civil Aviation Organization (ICAO) (Juan et al., 2017, 2018).

Following Juan et al. (2018), the instantaneous AATR is computed as

$$
\operatorname{AATR}_{i}^{j}(t)=\frac{1}{(M(\varepsilon))^{2}} \frac{\Delta s \operatorname{TEC}_{i}^{j}(t)}{\Delta t},
$$

where $\Delta \operatorname{sTEC}_{i}^{j}(t)$ corresponds to the variation between two consecutive slant TEC observations considering the receiver $i$ and the satellite $j, \Delta t$ is the sampling rate of the carrier-phase measurements. $M(\varepsilon)$ is the slant factor described in equation (4). The AATR index is then calculated by taking the RMS of the instantaneous $\mathrm{AATR}_{i}^{j}$ calculated for a pre-defined period $T$ for all $j$ satellites in view for a particular receiver $i$, according to:

$$
\operatorname{RMS}_{\mathrm{AART}_{, i}}(T)=\sqrt{\frac{1}{N} \sum_{t=T}^{T+\Delta T} \sum_{j=1}^{n_{\mathrm{sat}}(t)}\left(\operatorname{AATR}_{i}^{j}(t)\right)^{2}},
$$

where $N$ is the total number of observations during the interval $\Delta T(5$ min or $1 \mathrm{~h})$, after summing all satellites in view, $n_{\text {sat }}(t)$, at every epoch $t$ (Juan et al., 2018). In this work we have employed an interval $\Delta T$ of $5 \mathrm{~min}$. An example map is shown in Figure 2. The AATR data used herein is provided by the Universitat Politécnica Catalunya (UPC) via the TechTIDE warning service (http://tech-tide.eu), which grants open access 

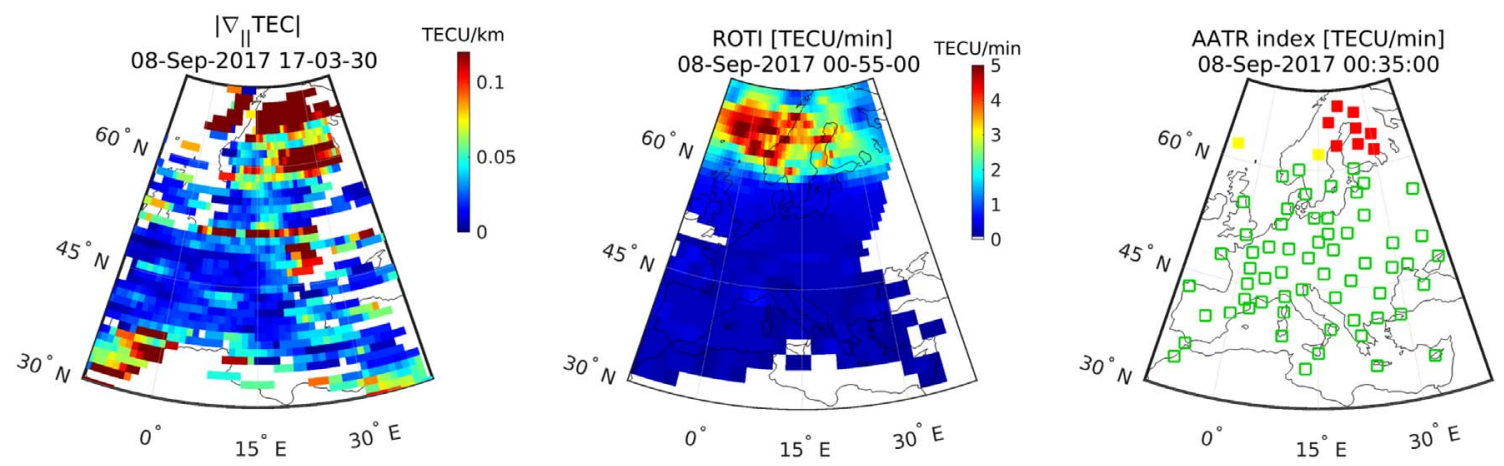

Fig. 2. Example maps of TEC gradients (left), ROTI (center) and AATR index (right) in three different levels: AATR $\leq 0.5$ (green); $0.5<$ AATR $\leq 1$ (yellow); AATR $>1$ (red).

to real-time and archived results of the main TID detection methods from the TechTIDE project.

\subsection{Rate of TEC index}

One of the potential precursors for the LSTIDs occurrence investigated herein is the Rate of TEC index (ROTI). In this work, we used the ROTI data provided by the Norwegian Mapping Authority (NMA), which operates a national network of GNSS receivers for positioning services and other investigations (Jacobsen \& Dähnn, 2014). In addition, we have included the ROTI provided by the Ionosphere Monitoring Prediction Center (IMPC) which process GNSS data in real-time to generate TEC and ROTI maps (Berdermann et al., 2018). Combined NMA and IMPC data sources can provide a good coverage over high and mid-latitude Europe.

Defined as the standard deviation of the Rate of TEC (ROT) over a certain interval, the ROTI is a commonly used index to measure the ionospheric irregularities level (Pi et al., 1997; Jacobsen, 2014; Cherniak et al., 2018). It is based on the ROT which can be computed as

$$
\operatorname{ROT}(i)=\frac{L_{\mathrm{GF}}(i)-L_{\mathrm{GF}}(i-1)}{\Delta t \times 10^{16} \times 40.3 \times\left(\frac{1}{f_{1}^{2}}-\frac{1}{f_{2}^{2}}\right)},
$$

where $L_{\mathrm{GF}}(i)$ is the geometry-free phase combination at epoch $i$ given by $L_{\mathrm{GF}}(i)=L_{1}(i) \times \lambda_{1}-L_{2}(i) \times \lambda_{2}$, with $L_{n}$, $\lambda_{n}$, and $f_{n}$ corresponding to the phase measurement, wavelength and frequency for the $n$th frequency, respectively. $\Delta t$ is the time difference between the epochs, in minutes (Jacobsen, 2014).

The ROTI is given in TECU/minute and is calculated over $N$ epochs as

$$
\operatorname{ROTI}(i)=\sqrt{\frac{1}{N} \sum_{j=i-N}^{i}(\operatorname{ROT}(j)-\overline{\mathrm{ROT}})^{2}} .
$$

In Figure 2 we present an example of ROTI map for the European region on 8th September 2017. In this work, the ROTI data are provided with a spatial resolution of $1^{\circ}$ latitude $\times 1^{\circ}$ longitude, with a 5 min cadence. The NMA ROTI is calculated over a $5 \mathrm{~min}$ interval (using $1 / 30 \mathrm{~Hz}$ data), whereas IMPC ROTI is obtained over $1 \mathrm{~min}$ interval (using $1 \mathrm{~Hz}$ data). Despite the different methods of computation, we have decided to combine the two database (NMA ROTI for latitudes above $50{ }^{\circ} \mathrm{N}$ and IMPC ROTI for latitudes below $50{ }^{\circ} \mathrm{N}$ ) in order to have a good coverage over Europe. Therefore, we point out that this difference has to be considered in the results of our analysis.

\subsection{TEC gradients}

Given the threat that TEC gradients can impose on GNSS services, these gradients, associated with geomagnetic storms and other phenomena (like plasma bubbles), have been investigated over the years (e.g., Mayer et al., 2009; Cesaroni et al., 2015). Regarding the purpose of the present work, as presented in Borries et al. (2017), the TIDs source regions can be associated with strong TEC gradients and therefore, these gradients could be a potential precursor for LSTIDs occurrence. In order to investigate this applicability, we use the single GPS receiver station method described in Pradipta \& Doherty (2015) and Mayer et al. (2008) to infer the magnitude of the spatial TEC gradients based on the observed temporal change in TEC, as follows

$$
\left|\nabla_{\|} \mathrm{TEC}\right|=\frac{\left|\operatorname{vTEC}\left(t_{1}\right)-\operatorname{vTEC}\left(t_{2}\right)\right|}{d s},
$$

where $d s$ corresponds to the distance travelled by the ionospheric pierce-point (IPP) from the instant $t_{1}$ to instant $t_{2}$. This method provides an estimate of the TEC gradient along the IPP trajectory and it has the advantage of not being highly sensitive to errors in the receiver bias computation (Pradipta $\&$ Doherty, 2015). From equation (10) one can note that the gradients presented herein contain spatial and temporal information that cannot be separated. However, it can be used as an indicator for disturbances in the ionosphere (Mayer et al., 2009). The TEC gradients used herein are obtained by using a time difference $\left(t_{1}-t_{2}\right)$ of $1 \mathrm{~min}$ and are derived from the GNSS TEC data presented in Section 2.1.

\subsection{IMAGE Equivalent Currents}

IMAGE Equivalent Currents (IEC) represent the ground magnetic disturbance caused by ionospheric currents. The IEC are calculated from measurements of the International Monitor for Auroral Geomagnetic Effects (IMAGE) magnetometer network and the result is projected to the ionospheric plane. Thus, the IEC are horizontal equivalent ionospheric currents 
which correspond to the observed ground magnetic field. It is important to point out that, in reality, the true ionospheric currents correspond to a combination of horizontal and field-aligned currents, and it is not possible to distinguish those by using ground magnetometer data only (Pulkkinen et al., 2003; Dimmock et al., 2019). The IEC provide valuable information about the ionospheric electrodynamics and magnetosphere-ionosphere coupling and it is derived by the Finnish Meteorological Institute (FMI) using the spherical elementary current system method (Amm, 1997; Amm \& Viljanen, 1999; Pulkkinen et al., 2003). IMAGE magnetometer measurements and derived IEC can be obtained via IMAGE web page (https://space.fmi.fi/image/).

\subsection{Swarm field-aligned currents and auroral oval boundary estimation}

The field-aligned currents (FACs) play an important role in the energy coupling between the magnetosphere and the upper atmosphere at auroral latitudes. Therefore, the knowledge of their intensity and distribution is relevant for studies of the magnetosphere-ionosphere interactions. One way to obtain the FACs is by applying the Ampére's integral law to the magnetic field measurements from Low Earth Orbiting (LEO) satellites (e.g., Lühr et al., 1996; Ritter et al., 2013). In our work, we used the Level-2 product of Swarm FACs data provided by the European Space Agency (available at http://swarm-diss.eo.esa.int/), and used the FACs to estimate the boundaries of the auroral oval using the method described in Xiong et al. (2014). In this method, the auroral oval boundaries are based on the $S$ variable, which was introduced by Heilig \& Lühr (2013) to represent the FACs intensity. This variable is given by a boxcar averaging over a 20s window length applied to the logarithm of the squared FACs density $\left(S=\left\langle\log _{10} j_{\|}^{2}\right\rangle_{20 s}\right)$. The values of $S$, as a function of latitude, are obtained for the four high-latitude segments, from $\pm 40^{\circ}$ Apex latitude (see, Richmond, 1995) to the magnetic pole in the north and south hemispheres. For each segment, the auroral boundary is then estimated via an iterative process consisting of finding the linear parts of the $S$ curve with steepest gradient.

\subsection{MFACE field-aligned currents}

One of the FACs estimates used in this work is obtained from the model of field-aligned currents through the empirical orthogonal function analysis (MFACE). It is an empirical high-resolution model of FACs based on 10 years of CHAMP measurements. Empirical orthogonal functions are used to model FACs in separate magnetic local time sectors (He et al., 2014).

The model inputs are the interplanetary magnetic field (IMF), solar wind speed and AE index. We used IMF and solar wind speed measurements from the Advanced Composition Explorer (ACE) MAG and SWEPAM instruments (http:// www.srl.caltech.edu/ACE/ASC/level2/) and AE index provided by the Kyoto World Data Center for Geomagnetism (http://wdc. kugi.kyoto-u.ac.jp/).

\subsection{Precipitation from DMSP}

The auroral particle precipitation plays an important role in the energy input to the high-latitude ionosphere, and the characteristics of the precipitating spectra can provide useful information about the energy transfer process. In this work, the data used to investigate the contribution of the particle precipitation are derived from the Defense Meteorological Satellite Program (DMSP) low Earth orbit satellites F16A, F17A and F18A. These are polar orbit satellites with an inclination of $98.9^{\circ}$, nominal period of $101 \mathrm{~min}$, and altitude of $840 \mathrm{~km}$. Modern payloads include the Special Sensor J (SSJ) instruments which are designed to measure precipitating auroral particles and have been supporting a variety of operational and research products including energy inputs, auroral boundary identification, spacecraft charging, and field-aligned currents (Redmon et al., 2017). DMSP SSJ data used in this work are available at the CEDAR Madrigal Database.

\subsection{0 lonosonde data}

Since TIDs reflect changes in the ionospheric electron density, ionosondes are an ideal sensor to detect and monitor them. In this study we use the Digisondes DPS-4D located at Pruhonice (URSI code PQ052, 50.0 $\mathrm{N} 14.6^{\circ} \mathrm{E}$ ) and Juliusruh (URSI code JR055, 54.6 $\mathrm{N} 13.4^{\circ} \mathrm{E}$ ). Both stations are in the mid-northern European area, about $500 \mathrm{~km}$ north-south from each other and belong to the ionosonde data providers for the real-time TechTIDE warning system (Belehaki et al., 2019). The ionograms derived from Juliusruh ionosonde were obtained with a time resolution of $5 \mathrm{~min}$. For Pruhonice, after the storm onset, a special campaign of higher temporal resolution was used (2 min, instead of the standard $15 \mathrm{~min}$ resolution). Frequency settings for the ionograms were modified manually within the main phase of the storm according to actual critical frequency values. The ionograms with higher resolution were recorded with the ordinary mode only, but at each $15 \mathrm{~min}$ the ionograms were obtained with the ordinary and extraordinary modes (Mosna et al., 2020).

For an operational use, such as HF propagation predictions or statistical long-term studies of ionospheric characteristics, data from automatic scaled ionograms available on the GIRO web portal (Global Ionospheric Radio Observatory Reinisch \& Galkin, 2011) provides a good accuracy. However, under geomagnetically disturbed conditions, with degraded critical frequencies (ionospheric $\mathrm{G}$ conditions, i.e. when the critical frequency of the F2 layer is equal to or less than that of the F1 layer, Piggott \& Rawer, 1972), spread F echoes or even outblanked F layer echoes due to auroral E layer signatures, the automatic scaling of ionograms by the scaling software ARTIST (Galkin \& Reinisch, 2008) partly fails (see Supplementary Material, Figure S1). Therefore, ionospheric characteristics derived from automatic ionogram scaling are not always suitable for such specific case studies like discussed in this paper. These ionograms should be inspected and scaled manually, which was done by the station operators according to the Ionogram Scaling Rules. Nevertheless, there may be uncertainties in the evaluated and derived parameters of up to several tens of kilometers in height and up to a few hundreds of $\mathrm{kHz}$ in frequency, which are due to the sometimes ambiguous interpretation of the ionogram echoes and traces under these dynamic ionospheric conditions. Especially spread F dominated ionograms are tricky to interpret and scale. 
07.09.2017

08.09.2017
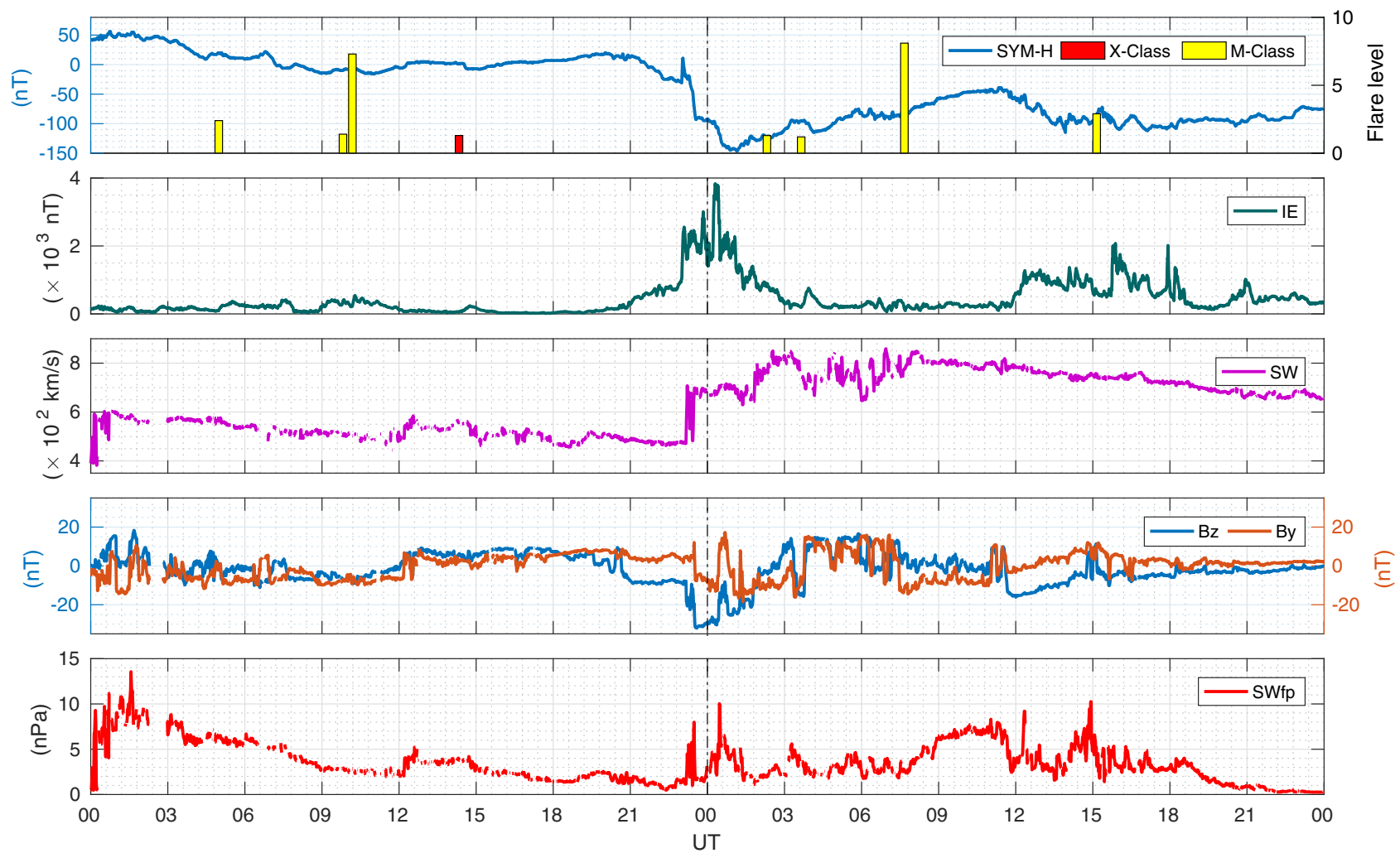

Fig. 3. Space Weather conditions during 8th September 2017, shown with common parameters. Top panel: solid line is geomagnetic SYM-H index. Bars indicate occurrence of solar flares. Second panel: Auroral electrojet index derived from IMAGE magnetometers (IE). Third panel: solar wind speed (SW). Fourth panel: $Y$ and $Z$-components of the interplanetary magnetic field $(B y, B z)$ in the geocentric solar magnetospheric (GSM) coordinates. Last panel: Solar wind flow pressure (SWfp). The solar wind data presented herein corresponds to the 1-min averaged values and involves the Earth's bow shock nose shifted ACE and WIND data available from the NASA'S OMNIWeb data service (http:// omniweb.gsfc.nasa.gov/).

\section{Space weather conditions on 8th September 2017}

Multiple coronal mass ejections (CMEs) associated with a X9.3-class solar flare on 6th September 2017, reached the Earth's bowshock on 7th September 2017 around 23:04 UT, and triggered a geomagnetic storm with a double main phase (Aa et al., 2019; Jin et al., 2018). The two main phases of the geomagnetic storm resulted in two periods of intense auroral activity, as indicated by the IMAGE electrojet index (IE) presented in Figure 3, second panel. During the first period, the auroral activity increased, with the IE index reaching a maximum of almost $4000 \mathrm{nT}$ at 00:18 UT. The ring current index SYM-H decreased, indicating the first main phase of the storm, and reached a minimum value of $-146 \mathrm{nT}$ on 8 th September at 1:08 UT (see Fig. 3, first panel). A second period of intense auroral activity started on 8th September 2017 at 11:55 UT. The ring current index SYM-H decreased, indicating the second main phase of the storm, and reached a second minimum of $-115 \mathrm{nT}$ at 13:56 UT. The two periods of enhanced auroral activity were related to the periods of southward directed IMF (cf. Fig. 3, fourth panel). A few M-class flares did occur on the 7th and the 8th of September 2017. An additional X-class flare did occur on 7th September 2017 14:20 UT (see Fig. 3, first panel). Solar wind speed increased with the arrival of the first CME and remained high during 8th September 2017 (see Fig. 3, third panel).

\section{Results}

\subsection{LSTIDs and potential precursors}

In order to analyze the temporal evolution of the concurrent perturbations in detrended TEC, AATR index, ROTI and TEC gradients, we generate time-latitude plots (TLP) for each parameter (Fig. 4). Each TLP shows the TEC perturbations at the $15^{\circ} \mathrm{E}$ longitude between 37 and $70^{\circ} \mathrm{N}$ geographic latitudes.

The detrended TEC shows very strong amplitudes of above 0.5 TECU after the onset of both periods of auroral activity intensification. The high latitude TEC perturbations in detrended TEC, which appear like random fluctuation, start on 7th September 2017 at around $18 \mathrm{UT}$ at $70^{\circ} \mathrm{N}$ and extend equatorward with time. Around 23 UT, they reach down to $58^{\circ} \mathrm{N}$. The perturbations are seen at these latitudes until about 02:00 UT the next day and tend to relocate poleward until they disappear from the map around 06:00 UT. On 8th September 

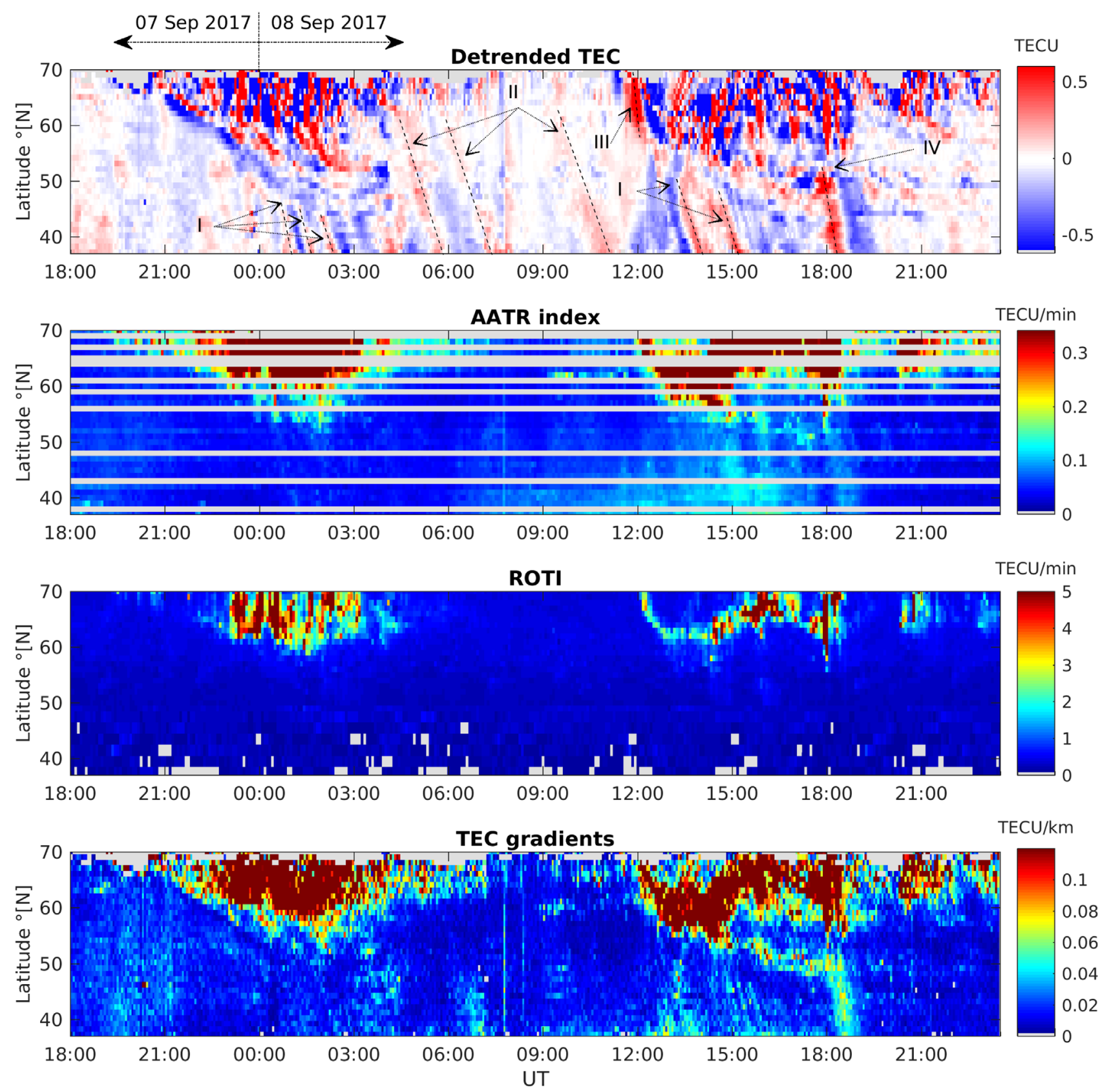

Fig. 4. Time-latitude-plots centered at $15^{\circ} \mathrm{E}$ of perturbations in the Total Electron Content (TEC) from 7th Sep 2017 (18:00 UT) to 8th Sep 2017 (23:59 UT), estimated with the different methods described in Section 2. First panel: Detrended TEC mostly reflecting TID amplitudes, where I corresponds to the group of fast LSTIDs in mid-latitudes, II corresponds to the group of slow LSTIDs, III corresponds to a significant strong wave-like TEC perturbation in high latitudes, IV corresponds to a strong LSTID in mid-latitudes generated in high-latitudes around 18 UT. Second panel: AATR index. Third panel: ROTI. Fourth panel: TEC gradients. Data gaps are presented in gray color.

after 11:00 UT, a significant very clear wave-like perturbation occurs at high latitudes and moves equatorward rapidly until it disappears only half an hour later at around $58^{\circ} \mathrm{N}$ (see Supplementary Material, Movie_S1). This wave-like feature is marked as III in Figure 4. In contrast to the other high-latitude TEC perturbations in the detrended TEC, this wave-like feature has a very long zonal extent parallel to the auroral oval, as visible in the detrended TEC maps. After this wave-like perturbation disappears, the typical high-latitudes perturbations, which do not show clear wave characteristics, persist. At 13 UT, they are located between around $58-70^{\circ} \mathrm{N}$. With proceeding time, they extend more and more equatorward. At $17 \mathrm{UT}$, they can be observed between around 45 and $70^{\circ} \mathrm{N}$. At $18 \mathrm{UT}$, the situation suddenly changes. High-latitude TEC perturbations appear back at higher latitudes and around 18:30 UT their activity reduces significantly for the following $2 \mathrm{~h}$. 


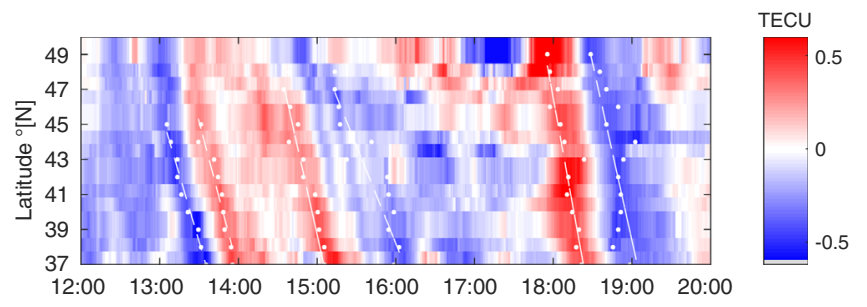

Fig. 5. Illustration of the linear fitting procedure used to estimate the LSTIDs propagation parameters on 8th September 2017, between 12:00 and 20:00 UT. White dots indicate the points for the linear fitting of crests and troughs, and the fitting results are indicated with white dashed-lines.

At the equatorward edge of the high-latitude perturbations, the detrended TEC often shows signatures that look like slanted rays. This is the signature of AGWs, observed in TEC, which we call LSTIDs. The size and the tilt of the slanted rays provide the information about wavelength, velocity and period. The parameters of the observed disturbances are obtained based on the method described in Liu et al. (2019) in which the linear least-square method is used to fit pairs of crests and troughs for each disturbance, as depicted in Figure 5. The white dots are the minimum and maximum values around the trough and crest, respectively. Based on the slope of the fitting lines (white lines), the velocity of crest $\left(v_{\mathrm{c}}\right)$ and trough $\left(v_{\mathrm{t}}\right)$ are estimated. The LSTID velocity is then considered as the mean value of $v_{\mathrm{c}}$ and $v_{\mathrm{t}}$. The period of the disturbance is estimated based on the time interval between trough and crest in the TLPs. The half-period of the disturbance is set as the averaged value of the time intervals between crest and trough observed at each latitude. The wavelength is then obtained from the multiplication of the speed and period. It is important to highlight that the extracted information corresponds to the zonal projection (centered in $15^{\circ} \mathrm{E}$ ) of the LSTIDs. Moreover, it should be noted that the GNSS coverage at mid-latitudes is lower than the coverage at high-latitudes. Therefore, in order to reduce data gaps and then perform the propagation parameters estimation, the detrended TEC is averaged along a $10^{\circ}$ band (centered in $15^{\circ} \mathrm{E}$ ) for each latitude. This procedure, although useful, may influence to a certain extent the accuracy of the estimation of LSTIDs propagation parameters in mid-latitudes. However, we consider this to have a minor impact on the propagation parameters estimation, because usually LSTID wave-fronts have thousands of kilometers longitudinal extend (Zakharenkova et al., 2016).

On 8th September at around 7:45 UT, there occurs a signature at all latitudes the same time (looks like a vertical red line). This can be caused by either solar flares or prompt penetration electric fields (PPEF). In this case, it is caused by a strong M-class flare, which is indicated in Figure 3 at exactly this time. There is no indication of sources for PPEF at this time, like a reversal of the IMF $B z$ component.

A few LSTIDs occur between 0 and 3 UT on 8th September (indicated as I in Fig. 4). They are not well visible and seem to interfere with other perturbations. Their properties are about $1900 \mathrm{~km}$ wavelength, $40 \mathrm{~min}$ period and $780 \mathrm{~m} / \mathrm{s}$ phase velocity. During the morning, there occur LSTIDs with longer wavelength (approx. $2900 \mathrm{~km}$ ), period of around $110 \mathrm{~min}$ and phase velocity about $430 \mathrm{~m} / \mathrm{s}$. These LSTIDs are marked as II in Figure 4. From 13-16 UT two LSTIDs with velocities of about $520 \mathrm{~m} / \mathrm{s}$ are also observed. These LSTIDs present periods of 50 and $100 \mathrm{~min}$, and wavelengths of around 1600 and $3000 \mathrm{~km}$, respectively and are indicated as I in Figure 4. A comparably strong large-scale wave is suddenly generated at $18 \mathrm{UT}$ at about $53^{\circ} \mathrm{N}$ (indicated as IV in Fig. 4), when the high-latitudes perturbations move back polewards. It is a single wave with very long wavelength $(\approx 3300 \mathrm{~km})$, period of around $80 \mathrm{~min}$ and typical phase velocity $(\approx 730 \mathrm{~m} / \mathrm{s})$ of LSTIDs during disturbed conditions.

The TLP of AATR index (Fig. 4, second panel) shows data gaps, because AATR is measured at the location of GNSS stations only and the density of the GNSS stations is not sufficient to fill the TLP completely. Still, the amplitudes of AATR are well visible. AATR indicates TEC perturbations in the high-latitude range between 60 and $70^{\circ} \mathrm{N}$ between 23-03 UT in the night from 7th to 8th September and between 12-18:30 UT and 20:30-21:00 UT. It corresponds with the times when the detrended TEC shows high-latitudes perturbations. At 17:55 UT, AATR peaks to extreme values with amplitudes exceeding 2.3 TECU/min. It does not remain more than $5 \mathrm{~min}$.

The TLP of ROTI look rather similar to that of AATR. There are individual data gaps in lower latitudes due to sparse data coverage. Here, the same high-latitude TEC perturbations are indicated as in AATR, but they seem to be confined further north. On 8th September 2017, between 12:00 and 12:30 UT, a very sharp TEC perturbation moves equatorward from 70 to $60^{\circ} \mathrm{N}$ and it remains at $60^{\circ} \mathrm{N}$ for two hours before it moves poleward again and intensifies in amplitude and horizontal extend. At 18:00 UT, there occurs a very sharp peak of ROTI with an amplitude of up to $10 \mathrm{TECU} / \mathrm{min}$. Amplitudes that high are rarely observed in ROTI. It does not remain more than 5 min. In mid-latitude regions ROTI does not increase. As pointed out in Section 2.4, the ROTI computation is different for latitudes above and below $50^{\circ} \mathrm{N}$. Since IMPC ROTI presents higher sample rate and short calculation time interval (1 min) than NMA ROTI, one can expected that it would present higher values than if it was calculated as the NMA ROTI for the same region (Jacobsen, 2014). However, even with those characteristics, no significant increasing on ROTI was observed in latitudes below $50^{\circ} \mathrm{N}$.

In the TEC gradients and AATR, more structures seem to be visible than in ROTI. The high-latitude perturbations are similar, but seem to reach a larger horizontal extend. Next to this, weaker TEC gradients are visible in mid-latitudes, where LSTIDs are present. Remarkable is a thin band of TEC gradients which start at around $15 \mathrm{UT}$ at $53^{\circ} \mathrm{N}$ and move equatorward. At around $17 \mathrm{UT}$, the thin band of TEC gradients is located at $50^{\circ} \mathrm{N}$. In comparison with the detrended TEC, this thin band of TEC gradients is located in the transition region between high-latitude perturbations and LSTIDs in midlatitudes. At 18 UT, a TEC gradient with moderate amplitude occurs at about $50^{\circ} \mathrm{N}$ and moves then equatorward. It is associated to the signature of the single strong LSTID observed in the detrended TEC (indicated as "IV', on Fig. 4, first panel), because it occurs at the same time with the same wavelength $(\approx 3300 \mathrm{~km})$ and phase velocity $(\approx 730 \mathrm{~m} / \mathrm{s})$. 

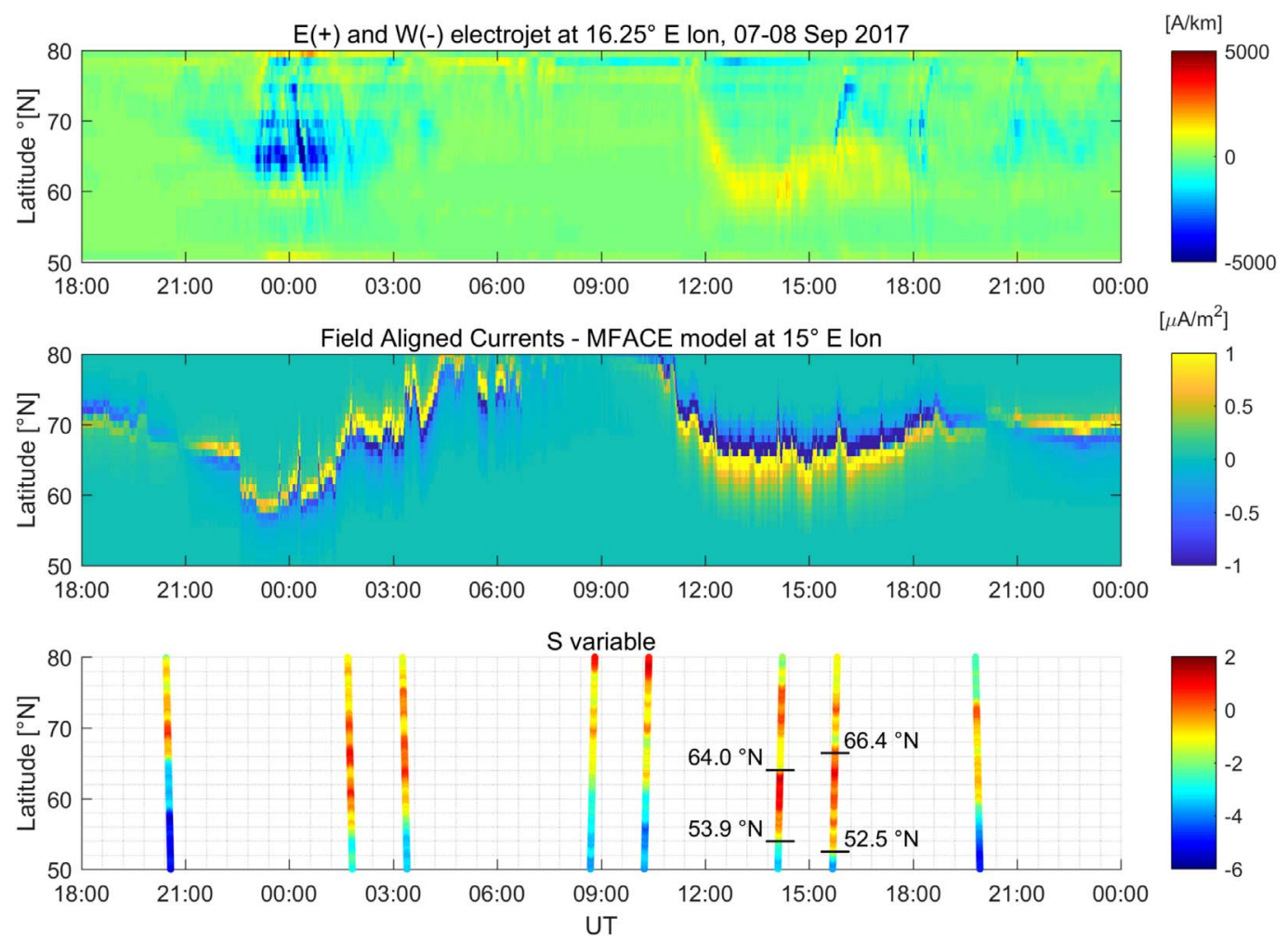

Fig. 6. Upper panel: Ionosphere Equivalent Currents (IEC), which indicate auroral electrojet activity (positive: eastward electrojet, negative: westward electrojet). Middle Panel: Field Aligned Currents (FAC), derived from MFACE model. Lower panel: S variable obtained from the Field Aligned Currents derived from Swarm constellation. Latitude coordinates correspond to the coordinates of Swarm satellites (vertical projection to the ground). Estimates of equatorward auroral oval boundaries and their geographic latitudes are indicated as black horizontal lines.

\subsection{Dynamics in the thermosphere-ionosphere}

\subsubsection{Relation of TEC perturbations to FAC and the auroral electrojet activity}

In order to investigate the contribution of ionospheric currents to the LSTIDs excitation, we analyse the IEC, and the FACs derived from the MFACE model and Swarm mission measurements shown in Figure 6. We would like to point out that in this section, in addition to the geographic latitudes, we also present some of the observations in Apex magnetic latitudes (Richmond, 1995). In these cases the observations have been projected along the field line to the altitude at $\mathrm{E}$ region $(110 \mathrm{~km})$, enabling the direct comparison of observations from different instruments.

Figure 6 shows a clear enhancement of the IEC during the two phases of the storm (night from 7th to 8th September and afternoon of 8th September). During the first main phase there occurs an enhancement and equatorward shift of the westward electrojet from $70^{\circ} \mathrm{N}$ to $62^{\circ} \mathrm{N}\left(67^{\circ} \mathrm{N}\right.$ to $59^{\circ} \mathrm{N}$, apex latitude). This equatorward shift of currents is also observed in the FACs obtained from the MFACE model. According to the MFACE model, the FACs seem to be located at the equatorward edge of the westward electrojet. Swarm FAC in situ data represented by the $S$ variable (Fig. 6, lower panel) are shown to verify the MFACE model data. The $S$ variable also shows an equatorward movement of FAC boundaries during the first main phase of the storm, reaching latitudes $\sim 54^{\circ} \mathrm{N}\left(52^{\circ} \mathrm{N}\right.$, apex latitude). This is significantly more equatorward than the model prediction. This equatorward shift of currents, which is linked to an expansion of the auroral oval, relates well with the equatorward expansion of strong high-latitude TEC perturbations observed on the detrended TEC (Fig. 4, upper panel). Thus, the high-latitude TEC perturbations seem to be located within the auroral oval.

During the second main phase of the geomagnetic storm, an intensification of the eastward electrojet occurs around 12 UT and it shifts equatorward from $72^{\circ} \mathrm{N}$ to $60^{\circ} \mathrm{N}\left(69^{\circ} \mathrm{N}\right.$ to $56^{\circ} \mathrm{N}$, apex latitude) within very short time (less than $1 \mathrm{~h}$ ). After that the eastward electrojet remains located at $60^{\circ} \mathrm{N}$ $\left(56^{\circ} \mathrm{N}\right.$, apex latitude) for about $1 \mathrm{~h}$, then it moves poleward again and reduces its intensity slightly. At 18 UT, the westward electrojet becomes dominant again. In general, the electrojet intensity during the second period of intense auroral activity is not as strong as the intensity of the westward electrojet during the first period. A similar location is reproduced by the MFACE model for the FACs (Fig. 6, middle panel). However, the model predicts stronger intensity of FACs in the second period of intense auroral activity relative to the first one. It is also important to note that during the second period of intense auroral activity Swarm measurements indicate FACs activity further equatorwards than what is indicated by the MFACE model. At 14:06 UT, Swarm B measures the equatorward edge of the auroral oval at $54^{\circ} \mathrm{N}\left(51.5^{\circ} \mathrm{N}\right.$, apex latitude) and at $15: 42 \mathrm{UT}$ it is at $52.5^{\circ} \mathrm{N}\left(50.4^{\circ} \mathrm{N}\right.$, apex latitude). The Swarm 
estimates of the auroral oval edge correspond well with the edge of high-latitude TEC perturbations, showing again that the highlatitude TEC perturbations are located within the auroral oval.

\subsubsection{Relation of TEC perturbations to particle precipitation}

For information about the occurrence of particle precipitation, we consulted Juliusruh and Pruhonice ionosonde measurements and DMSP satellite measurements. In ionosonde measurements, a particle precipitation is normally manifested by an enhanced Aurora $E$-layer, a sporadic $E$-layer like signature, but with slightly increasing heights with increasing frequency. For the afternoon of 8th September, no Aurora E was observed over Juliusruh. Hence no precipitation occurred at $54.6^{\circ} \mathrm{N}$, $13.4^{\circ}$ E. Occasionally, Pruhonice measures sporadic E-layer with increased heights in the time between 11:13-12:03 and 14:37-17:06 UT on 8th September (Mosna et al., 2020).
Juliusruh shows similar weak structures partly between 15:13 and 16:13 UT. But in both stations the observed structures have a duration of only few minutes and they do not show the typical Aurora E characteristics. Moreover, they have a cloudy, noncontinuous structure.

Interestingly, in the afternoon hours (after 17:30 UT) the ionograms in Juliusruh show strong oblique spread $\mathrm{F}$ echoes up to $1 \mathrm{MHz}$ frequency spread which are not reflected from the zenith, but slightly south, with zenith angles up to $20^{\circ}$. These oblique echoes indicate that the ionosphere is tilted in North-South direction with increasing heights from South to North. Also Pruhonice measurements show this kind of oblique echoes. Furthermore, between 14 and 16 UT, the F-region ionosphere over the two ionosondes is perturbed and does not have homogeneous horizontal structure.

Precipitation measurements from the DMSP satellites passing over the European sector during the afternoon of the 8th of September 2017 are shown in Figure 7. By observing the

\section{DMSP - 08/09/2017}
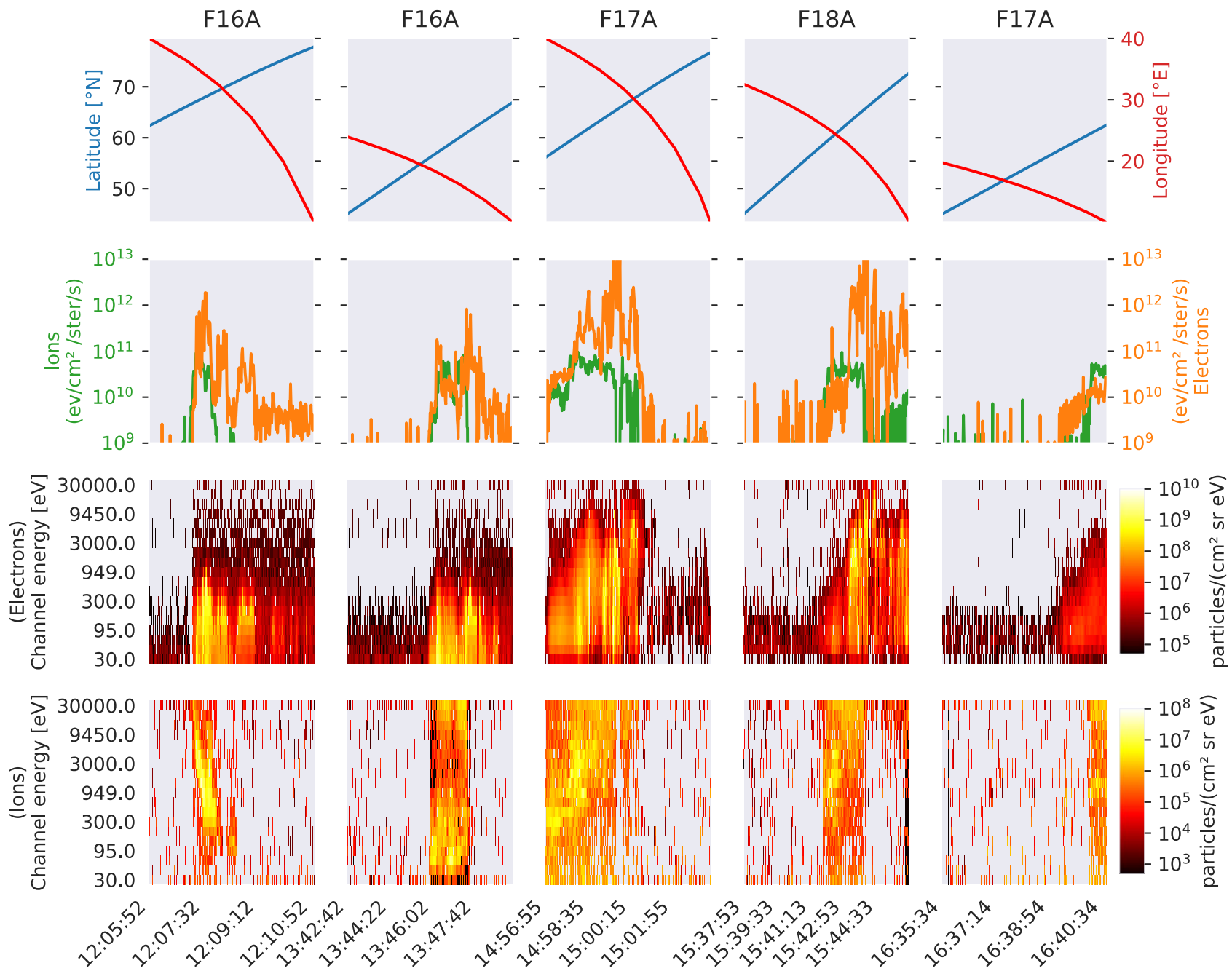

UT

Fig. 7. Selected DMSP crossings over Europe on 8th September 2017 for DMSP satellites F16A, F17A and F18A. First panel: Geographic coordinates of the satellite during the passage (vertical projection to the ground). Second panel: Integrated electron/ion energy flux. Third panel: Differential electron energy flux. Fourth panel: Differential ion energy flux. 
integrated and differential energy fluxes one can note that significant particle precipitation occurs in latitudes above $58^{\circ} \mathrm{N}$. This region has a good correspondence with the region where highlatitude perturbations are observed in the detrended TEC (Fig. 4, upper panel). This indicates that particle precipitation influences this region of strong ionospheric perturbations at high-latitudes. However, particle precipitation does not occur in the region further equatorward down to $52^{\circ} \mathrm{N}$, where we observe TEC gradients and auroral boundary signatures.

\section{Discussion}

\subsection{Applicability of indices as precursors for LSTIDs occurrence}

A precursor for the occurrence of LSTIDs is considered to be a parameter that exceeds a certain threshold before LSTIDs occur. As described in the earlier section, several different types of LSTIDs are observed during 8th September 2017:

I. Fast LSTIDs in midlatitudes between 0-3 UT and 13-16 UT;

II. Slow LSTIDs between 3 and 12 UT;

III. A significant strong wave-like TEC perturbation at high latitudes, which vanishes around $58^{\circ} \mathrm{N}$;

IV. A strong single LSTID at mid-latitudes generated at high latitudes around $18 \mathrm{UT}$.

These disturbances are indicated as I, II, III, and IV, respectively, in Figure 4, first panel. In the case of fast LSTIDs, AATR, ROTI and TEC gradients show significant amplitudes at high latitudes prior to the LSTID occurrence. Thus, they are all suitable candidates to be used as precursor for such ionospheric perturbations. However, the relation to LSTID occurrence seems to differ between these indices. While ROTI amplitudes are high only in latitude range between 60 and $70^{\circ} \mathrm{N}$, AATR and TEC gradient amplitudes follow more accurately the expansion of the strong ionospheric high-latitudes perturbation observed in the detrended TEC (Fig. 4, upper panel). The relation with LSTID occurrence is also reflected in moderate amplitudes in regions where LSTIDs occur. In addition, AATR and TEC gradients show the same boundary of high-latitude perturbations and mid-latitude LSTID occurrence (source region of LSTIDs which moves from $55^{\circ} \mathrm{N}$ at $15 \mathrm{UT}$ to $50^{\circ} \mathrm{N}$ at around $18 \mathrm{UT}$ ) which is visible in the detrended TEC. Although ROTI reflects high-latitude perturbations, the affected region does not cover the whole auroral region (as shown in the comparison with Swarm auroral oval boundaries Fig. 6). ROTI is known to indicate regions affected by auroral precipitation (Cherniak \& Zakharenkova, 2015) and the same behavior is also evident in this case study (comparing DMSP electron precipitation and ROTI in Figs. 2 and 7). Hence, ROTI does not cover well the source region of LSTIDs. In addition, ROTI does not reflect LSTIDs signatures at midlatitudes. This is in accordance with the results presented in Cherniak \& Zakharenkova (2018). Therefore, we consider AATR and TEC gradient indices to be more accurate in indicating the potential generation of LSTIDs.
There is no perturbation index that can serve as precursor for the slow LSTIDs observed in the morning hours (indicated as II in Fig. 4). It is likely, that they are related to the passage of the morning terminator, as shown in Cherniak \& Zakharenkova (2018). Therefore, no ionospheric perturbation index is suitable for predicting this kind of LSTIDs. They are considered to be a regular phenomenon with smaller amplitudes than those LSTIDs generated by auroral activity. Chum \& Podolská (2018) also discussed this kind of TIDs and showed that they can propagate in different directions.

The significant strong wave-like TEC perturbation at high latitudes (indicated as III in Fig. 4) is reflected in all the perturbation indices, indicating that this is not a free atmospheric oscillation, but a direct impact of auroral precipitation or ionospheric currents.

The strong single LSTID propagating at around 18 UT (indicated as IV in Fig. 4) occurs after all three ionospheric perturbation indices show significant spikes in their data. We attribute this LSTID to the same generation mechanism as the earlier discussed fast LSTIDs. However, in this case the driving mechanism is so intense that it is manifested by significant amplitudes of AATR, ROTI and TEC gradients.

Besides the analysis of LSTIDs, we would like to note that also signatures of flares are included in the presented results. The M-Class flare, which occurred on 8th September 2017 at 07:40 UT, is visible as a vertical line in the TLP of detrended TEC, AATR and the TEC gradients. Although signatures of flares in ROTI have been reported by Berdermann et al. (2018), ROTI does not depict the flare in this case study. It can occur due to the time interval of the ROTI calculation (5 min), which can remove/reduce short-lived peaks due to the inherent smoothing effect of the computation method (Jacobsen, 2014).

\subsection{Dynamics contributing to the generation of LSTIDs}

LSTID are understood to be generated by sudden strong heating in the auroral region. Heating occurs either due to dissipation of currents or precipitation. Often both effects will contribute to the strong heating. In our case study, LSTIDs are generated more frequently and with higher amplitude during periods with enhanced electrojet activity, indicated by increased IE index. Also the phase velocity seems to increase during periods with increased IE. This indicates, that not only the LSTID amplitude relates with auroral electrojet activity (as described in Borries et al., 2009), but also phase speed.

LSTIDs are supposed to start at the edge of the auroral oval, where the currents are located and particle precipitation occurs (Cherniak \& Zakharenkova, 2018). This seems to be valid for the LSTIDs observed in the night from 7th to 8th September and for the first LSTIDs of the second period of intense auroral activity (indicated as I in Fig. 4). But, there is a period between 15 and $18 \mathrm{UT}$, when the auroral oval boundary cannot be clearly identified, because horizontal currents and FAC are not in the same latitudinal region.

Starting around $15 \mathrm{UT}$, the region of the FAC location is several degrees equatorward of the location of the horizontal currents and the LSTID amplitudes become smaller for a few hours.

The LSTID source region coincides with the auroral oval boundary indicated by Swarm measurements and is characterized by enhanced TEC gradients, indicating electrodynamic 

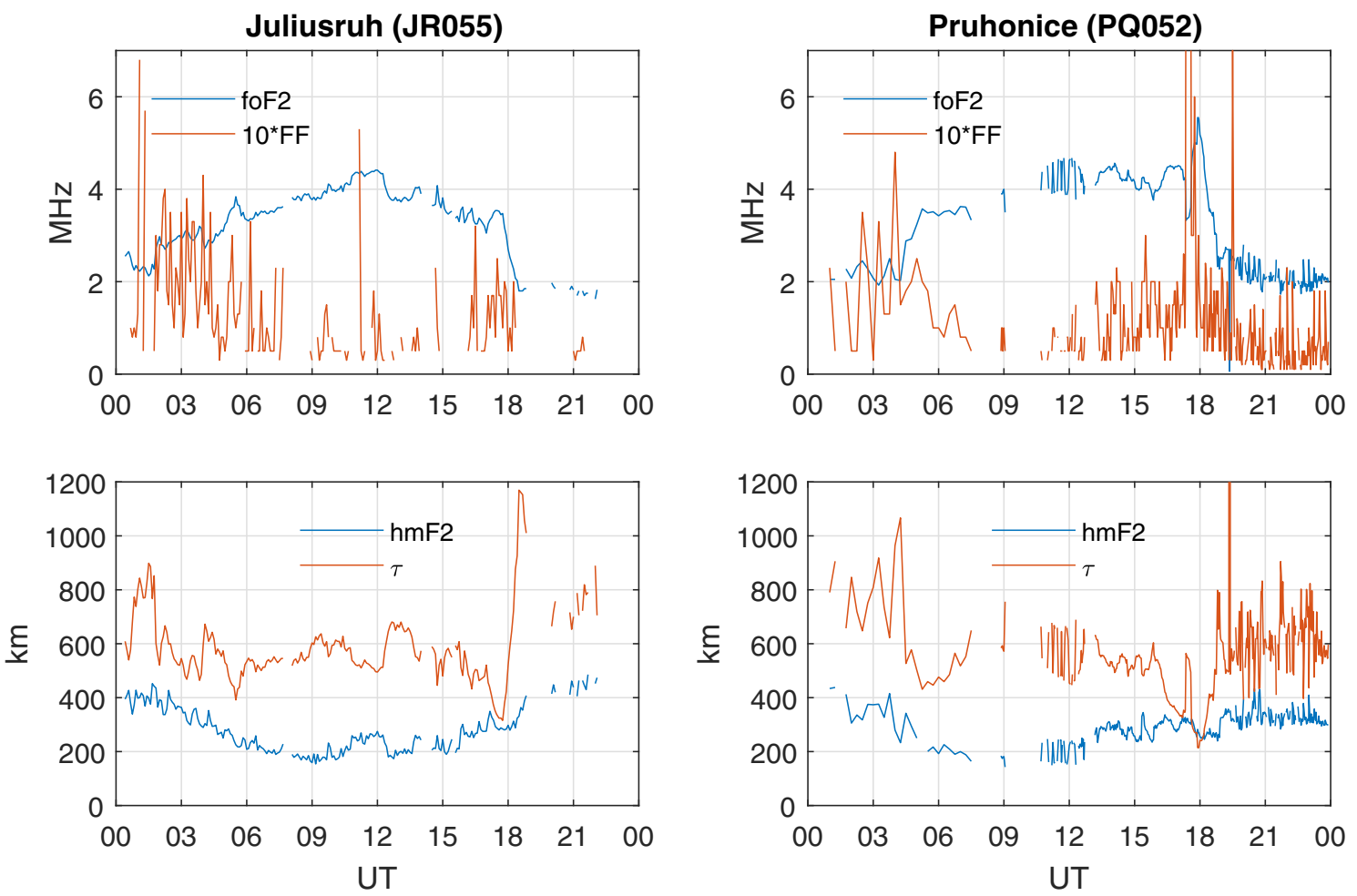

Fig. 8. Ionosonde measurements on 8th September 2017, at Juliusruh $\left(54.6^{\circ} \mathrm{N}, 13.4^{\circ} \mathrm{E}\right.$, left panels) and Pruhonice $\left(50.0^{\circ} \mathrm{N}, 14.6^{\circ} \mathrm{E}\right.$, right panels). Top: critical frequency $f o F 2$ and spread $F$ parameter $F F$. Bottom: Height of $F 2$-layer $h m F 2$ and equivalent slabthickness $\tau$.

processes in this region (Borries et al., 2017). Also, the typical strong high-latitude TEC perturbations, which are observed between the LSTID source region and the TEC gradients enhancement at about $50^{\circ} \mathrm{N}$, reflect auroral activity.

To support the unusual auroral activity in the region $50-55^{\circ} \mathrm{N}$, Figure 8 presents related measurements from the Juliusruh and Pruhonice ionosondes. Figure 8 (upper panel) shows the critical frequency $f_{o} F 2$ and the spread $F$ parameter FF ("URSI code 86"), which corresponds to the frequency spread between the critical $F$-layer frequency and the highest recorded $F$-layer echo for a specific wave mode, ordinary or extraordinary (Gamache \& Reinisch, 1990). Figure 8 (lower panel) presents the height of the maximum electron density $h m F 2$, and also the equivalent slab thickness $\tau$, which gives an approximation of the altitude range over which the electrons are spread. $\tau$, which is derived from $f o F 2$ and TEC, is a valuable parameter for characterizing ionosphere perturbations. It has already been used in Borries et al. (2017) for discussing LSTID generation mechanisms. Generally, $\tau$ is rather high on 8th September 2017. An unusually stratified $F$ layer is causing the large $\tau$ values. This is accompanied by an increased spread $F$ ( $F F$ parameter in Fig. 8) in Juliusruh and Pruhonice, starting at 12 UT. High $F F$ indicates plasma instabilities in the $F$-layer, e.g., bubbles occurring at this time, supporting the assumption that the ionosphere is not homogeneously layered. It is important to mention that the scatter in the variables presented in Figure 8 is related to uncertainties in the interpretation and manual scaling of the disturbed-time ionograms, as described in Section 2.10.

Between 16 UT and shortly before 18 UT, $f o F 2$, which is proportional to the maximum electron density of the F2-layer, increases and $\tau$ decreases. This shows a compression of the ionosphere to a thinner layer. Either northward winds or electric fields can cause the plasma transport leading to this change in electron density. Since and intensification of northward winds in mid-latitudes during a period of intense auroral activity is unlikely, electric fields are considered to be the source. Strong horizontal and vertical plasma drifts in this time interval are reported over Pruhonice in Mosna et al. (2020). Specifically, the westward plasma flow increases constantly between 14 and 18 UT reaching $400 \mathrm{~m} / \mathrm{s}$. This strong plasma flow is assumed to be caused by electric fields penetrating to sub-auroral latitudes (Foster \& Vo, 2002; Pokhotelov et al., 2008). These sub-auroral polarization streams, which occur between 15 and 18 UT, are considered to cause the observed TEC gradients between 50 and $55^{\circ} \mathrm{N}$ and unusual stratification of the $F$-layer at this time, too.

Very significant is the wave-like TEC perturbation on 8th September at around 11:30 UT at high latitudes (marked as III in Fig. 4). In contrast to the LSTID signatures, this wave-like perturbation is visible not only in the detrended TEC, but also in ROTI, TEC gradients and AATR. Since its amplitude is large compared to the other LSTIDs, it must have a strong forcing. The fact that it vanishes at around $58^{\circ} \mathrm{N}$ indicates that it is not a free wave but a forced wave, which disappears as soon as the forcing disappears. In Figure 6, it is shown that the eastward electrojet and FACs are located in the same region. They have enhanced intensity and move equatorwards from 80 to $60^{\circ} \mathrm{N}$ between 11:30 and 12:00 UT, the same way like the TEC perturbations. This indicates that the dislocation of the currents causes the wave-like TEC perturbation. The dislocation of 


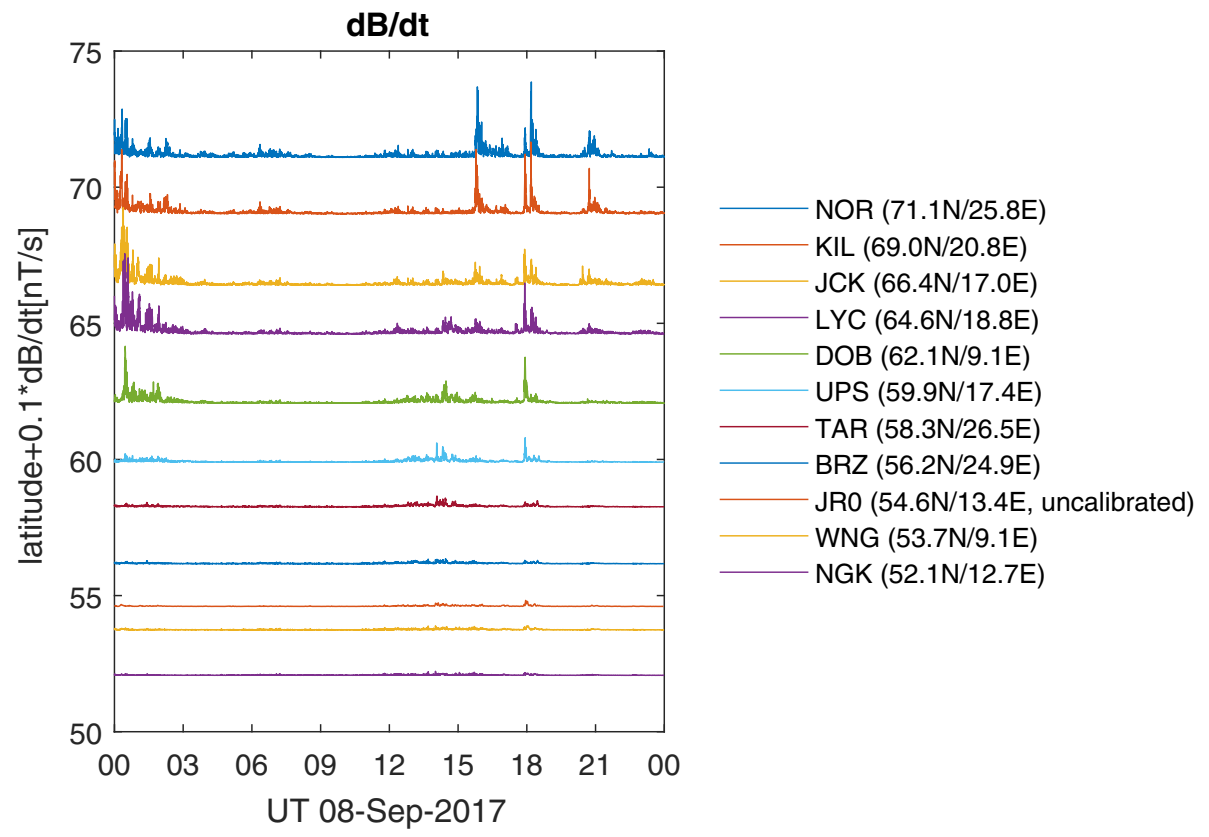

Fig. 9. Temporal change of geomagnetic magnetic field derived from different magnetometer stations.

the currents relates with a sudden equatorward shift of the cusp, which is reported in Yamauchi et al. (2018). It was attributed to the sudden IMF southward turning, resulting in a strong antisunward plasma convection flow observed near local noon by the Troms $\emptyset$ radar.

The single LSTID, generated at 18 UT on 8th September 2017, had a rather large amplitude compared to the other LSTIDs observed during this day. It must be related to intensive dynamics in the thermosphere-ionosphere-magnetospheresystem. This is not obvious from the Dst and IE indices, but it is indicated by the peaks in ROTI and AATR. Strong electrodynamic processes are also evident considering the results of Dimmock et al. (2019), who reported significant geomagnetically induced currents (GIC) at 18 UT in Fennoscandia. Since neither the solar wind and IMF, nor the geomagnetic indices show significant perturbations at that time, magnetosphereionosphere electrodynamics must be the source of the LSTID and the GIC.

Magnetometer measurements provided by the IMAGE network and Juliusruh station (JR0) reflect the perturbations of ionosphere currents by strong temporal changes in the geomagnetic field strength. Figure 9 shows that significant amplitudes of $\mathrm{d} B / \mathrm{d} t$ are apparent from high latitudes down to $60^{\circ} \mathrm{N}$. Although the magnitude of $\mathrm{d} B / \mathrm{d} t$ becomes smaller with decreasing latitude, the sudden increase of $\mathrm{d} B / \mathrm{d} t$ at $18 \mathrm{UT}$ is still visible at Niemegk $\left(\mathrm{NGK}, 52^{\circ} \mathrm{N}\right)$. Also the ionosonde measurements indicate a significant change in the electrodynamics a few minutes before $18 \mathrm{UT}$. While the westward plasma flow was increasing constantly between 14 and $18 \mathrm{UT}$, reaching a maximum value up to $400 \mathrm{~m} / \mathrm{s}$ shortly before $18 \mathrm{UT}$, it decreased significantly after this peak. In addition, $f \circ F 2$ starts to decrease significantly at both ionosonde stations a few minutes before 18 UT and $\tau$ increases significantly. This is a dramatic change in the plasma transport, because now the plasma is distributed over a very large altitude range. Since electric fields are considered to cause the plasma transport, a reversal of electric fields is considered to be the source of the extreme ionosphere perturbation at 18 UT. Figure 6 reveals that at the same time at higher latitudes the auroral electrojet also reverses from strongly eastward to westward and the FACs also reverse. This manifests the Harang discontinuity (Erickson et al., 1991), which normally occurs a few hours before midnight.

On 8th September 17:55 UT rapid changes in the ionosphere currents and changes in the electric fields trigger a GIC and a single strong LSTID. The significantly large LSTID starts at $53^{\circ} \mathrm{N}$ and moves equatorward with a speed of $\approx 730 \mathrm{~m} / \mathrm{s}$, a period of $\approx 80 \mathrm{~min}$ and a wavelength of $\approx 3300 \mathrm{~km}$.

After $18 \mathrm{UT}$, ionosphere perturbations reduce significantly for about $2 \mathrm{~h}$. Only the single large LSTID, which has been generated by the quick extreme enhancement of ionosphere currents, moves equatorward.

\section{Summary and Conclusions}

In this work the manifestation of the LSTIDs over midlatitude Europe has been analysed during the space weather events registered during the night of 7th-8th September 2017. The analyses included on the one hand the investigation of potential ionospheric perturbation indices that can serve as precursors for the LSTIDs occurrence and, on the other hand, the investigation of generation mechanisms for the observed LSTIDs via a detailed analysis of the electrodynamics.

GNSS data from ground-based stations have been used in this study to identify the LSTIDs and their different characteristics in amplitude, period and phase speed. The manifestation of fast LSTIDs in mid-latitudes has been observed between 0-3 UT and 13-16 UT; slow LSTIDs were observed between 3 and 12 UT; a forced wave-like perturbation at high-latitudes occurred around noon; and a strong and large LSTID at 
mid-latitudes was recorded around 18 UT. The weak and slow LSTIDs observed from 3 to 12 UT are likely to be induced by the morning terminator passage. Strong heating due to dissipation of currents and particle precipitation are concluded to be the main contributors for the other observed LSTIDs. However, particle precipitation was rather weak in the LSTID source region during the second period of intense auroral activity in this case study. The single rather strong and large LSTID observed around 18 UT was generated after a reversal of electric fields and auroral currents. This reversal caused sharp and very intense changes in the ionosphere currents that also triggered GIC in Fennoscandia.

The most pronounced LSTIDs occurred after strong ionospheric perturbations at high-latitudes. These high-latitude perturbations were reflected in significant amplitudes in TEC gradients, AATR index and ROTI. Often, LSTIDs signatures start at the equatorward edges of these high-latitude perturbations. AATR index and TEC gradients follow more accurately the expansion of the strong ionospheric high-latitude perturbation observed in the detrended TEC, which is caused by subauroral polarization streams. In addition, the boundary of high-latitude perturbations depicted in AATR index and TEC gradients shows good agreement with the source region of the LSTIDs. These results indicate that AATR index and the TEC gradients are promising candidates for near-real time indication and warning for the LSTIDs occurrence in mid-latitude Europe. Apart from the LSTIDs generated by storm dynamics, it must be considered that weak LSTIDs are a regular phenomenon in the morning hours. They are likely associated with the passage of the solar terminator. The terminator itself has to be considered as precursor for these LSTIDs.

Finally, we suggest statistical investigations to confirm the applicability of AATR index and TEC gradients as precursors for LSTID occurrence during storm conditions and to determine suitable thresholds for their use in LSTIDs warning systems.

Acknowledgements. This work is supported by the European Commission Horizon 2020 Project 776011 TechTIDE "Warning and Mitigation Technologies of Travelling Ionospheric Disturbances Effect".

The authors thank the Ionosphere Monitoring Prediction Center (IMPC) and the Norwegian Mapping Authority (NMA) for providing ROTI data and the Universitat Politècnica de Catalunya for providing AATR data. We also thank NASA/GSFC's OMINIWeb for providing solar wind and IMF data, the European Space Agency (ESA) for providing the SWARM data. We thank the ACE SWEPAM and MAG instrument teams and the ACE Science Center for providing the ACE data. We thank the DMSP, Boston College and CEDAR Madrigal teams for providing DMSP SSJ data. We also thank the institutes who maintain the IMAGE Magnetometer Array: Troms $\varnothing$ Geophysical Observatory of UiT the Arctic University of Norway, Finnish Meteorological Institute, Institute of Geophysics Polish Academy of Sciences, GFZ German Research Centre for Geosciences, Geological Survey of Sweden, Swedish Institute of Space Physics, Sodankylä Geophysical Observatory of the University of Oulu (Finland), and Polar Geophysical Institute (Russia).

We thank the Massachusetts Institute of Technology, who provide access to GNSS TEC data products through the
Madrigal distributed data system under support from US National Science Foundation grant AGS-1242204. Data for the TEC processing is provided by the following organizations: UNAVCO, Scripps Orbit and Permanent Array Center, Institut Geographique National, France, International GNSS Service, The Crustal Dynamics Data Information System (CDDIS), National Geodetic Survey, Instituto Brasileiro de Geografia e Estatística, RAMSAC CORS of Instituto Geográfico Nacional de la República Argentina, Arecibo Observatory, Low-Latitude Ionospheric Sensor Network (LISN), Topcon Positioning Systems, Inc., Canadian High Arctic Ionospheric Network, Institute of Geology and Geophysics, Chinese Academy of Sciences, China Meteorology Administration, Centro di Ricerche Sismologiche, Système d'Observation du Niveau des Eaux Littorales (SONEL), RENAG: REseau NAtional GPS permanent, GeoNet - the official source of geological hazard information for New Zealand, GNSS Reference Networks, Finnish Meteorological Institute, and SWEPOS - Sweden.

We highly appreciate also the support from Dimitry Pokhotelov from the German Aerospace Center for the very valuable comments and inputs.

The authors would like to thank the Brazilian agencies CNPq and FAPDF which partially supported this work.

The editor thanks Yaroslav Chum and an anonymous reviewer for their assistance in evaluating this paper.

\section{Suplementary Materials}

Supplementary materials (Figure S1 and Movie_S1) are available at https://www.swsc-journal.org/10.1051/swsc/ 2020029/olm

Figure S1: Two Juliusruh ionograms for the disturbed evening hours on $08^{\text {th }}$ September 2017. Both ionograms came out with wrong autoscaling results and derived electron density profiles but are able to be manually scaled with reasonable results. - The upper ionogram (17:53UT) shows a) spread echoes between $\sim 3$ and $>4 \mathrm{MHz}$, which corresponds to a Frequency Spread parameter FF $\sim 1 \mathrm{MHz}$ and b) non-vertical or oblique echoes ( $>15^{\circ}$ off-zenith) marked as coming from south directions (see right color legend).

Movie_S1: Wave-like ionospheric perturbation observed on 8th September 2017 after 11 UT.

\section{References}

Aa E, Zou S, Ridley A, Zhang S, Coster AJ, Erickson EJ, Liu S, Ren J. 2019. Merging of storm time midlatitude traveling ionospheric disturbances and equatorial plasma bubbles. Space Weather 17: 1-14. https://doi.org/10.1029/2018SW002101.

Altadill D, Segarra A, Blanch E, Juan JM, Paznukhov VV, Buresova D, Galkin I, Reinisch BW, Belehaki A. 2020. A method for realtime identification and tracking of traveling ionospheric disturbances using ionosonde data: first results. J Space Weather Space Clim 10(2): 1-11. https://doi.org/10.1051/swsc/2019042.

Amm O. 1997. Ionospheric elementary current systems in spherical coordinates and their application. J Geomag Geoelectr 49(7): 947-955. https://doi.org/10.5636/jgg.49.947. 
Amm O, Viljanen A. 1999. Ionospheric disturbance magnetic field continuation from the ground to the ionosphere using spherical elementary current systems. Earth Planets Space 51: 431-440. https://doi.org/10.1186/BF03352247.

Belehaki A, Galkin I, Borries C, Pintor P, Altadill D, et al. 2019. TechTIDE: Warning and mitigation technologies for travelling ionospheric disturbances effects. In: Berbers Y, Zwaenepoel W (Eds.), URSI Asia-Pacific Radio Science Conference, 1. URSI. https://doi.org/10.23919/URSIAP-RASC.2019.8738350.

Berdermann J, Kriegel M, Banyś D, Heymann F, Hoque MM, Wilken V, Borries C, Heßelbarth A, Jakowski N. 2018. Ionospheric response to the X9.3 flare on 6 September 2017 and its implication for navigation services over Europe. Space Weather 16 (10): 1604-1615. https://doi.org/10.1029/2018SW001933.

Borries C, Berdermann J, Jakowski N, Wilken V. 2015. Ionospheric storms - A challenge for empirical forecast of the total electron content. J Geophys Res Space Phys 120(4): 3175-3186. https://doi. org/10.1002/2015JA020988.

Borries C, Jakowski N, Kauristie K, Amm O, Mielich J, Kouba D. 2017. On the dynamics of large-scale traveling ionospheric disturbances over Europe on 20 November 2003. J Geophys Res Space Phys 122(1): 1199-1211. https://doi.org/10.1002/2016JA023050.

Borries C, Jakowski N, Wilken V. 2009. Storm induced large scale TIDs observed in GPS derived TEC. Ann Geophys 27: 1605-1612. https://doi.org/10.5194/angeo-27-1605-2009.

Bowman GG, Mortimer IK. 2011. Some aspects of large-scale travelling ionospheric disturbances which originate at conjugate locations in auroral zones, cross the equator and sometimes encircle the Earth. Ann Geophys 29(12): 2203-2210. https://doi. org/10.5194/angeo-29-2203-2011.

Cesaroni C, Spogli L, Alfonsi L, Francesci GD, Ciraolo L, Monico JFG, Scotto C, Romano V, Aquino M, Bougard B. 2015. L-band scintillations and calibrated total electron content gradients over Brazil during the last solar minimum. J Space Weather Space Clim 5(A36): 1-11. https://doi.org/10.1051/swsc/2015038.

Chen G, Zhou C, Liu Y, Zhao J, Tang Q, Wang X, Zhao Z. 2019. A statistical analysis of medium-scale traveling ionospheric disturbances during 2014-2017 using the Hong Kong CORS network. Earth Planets Space 71(52): 1-14. https://doi.org/10.1186/s40623019-1031-9.

Cherniak I, Krankowski A, Zakharenkova I. 2018. ROTI Maps: a new IGS ionospheric product characterizing the ionospheric irregularities occurrence. GPS Solutions 22(69): 1-12. https://doi.org/10.1007/s10291-018-0730-1.

Cherniak I, Zakharenkova I. 2015. Dependence of the high-latitude plasma irregularities on the auroral activity indices: a case study of 17 March 2015 geomagnetic storm. Earth Planets Space 67(151): 1-12. https://doi.org/10.1186/s40623-015-0316-X.

Cherniak I, Zakharenkova I. 2018. Large-scale traveling ionospheric disturbances origin and propagation: Case study of the December 2015 geomagnetic storm. Space Weather 16(9): 1377-1395. https://doi.org/10.1029/2018SW001869.

Chum J, Podolská K. 2018. 3D Analysis of GW propagation in the ionosphere. Geophys Res Lett 45(21): 11562-11571. https://doi. org/10.1029/2018GL079695.

Ciraolo L, Azpilicueta F, Brunini C, Meza A, Radicella SM. 2007. Calibration errors on experimental slant total electron content (TEC) determined with GPS. J Geod 81(2): 111-120. https://doi. org/10.1007/s00190-006-0093-1.

Curto JJ, Marsal S, Blanch E, Altadill D. 2018. Analysis of the Solar Flare Effects of 6 September 2017 in the Ionosphere and in the Earth's Magnetic Field Using Spherical Elementary Current
Systems. Space Weather 16(11): 1709-1720. https://doi.org/ 10.1029/2018SW001927.

Dimmock AP, Rosenqvist L, Hall J-O, Viljanen A, Yordanova E, Honkonen I, André M, Sjöberg EC. 2019. The GIC and geomagnetic response over Fennoscandia to the 7-8 September 2017 geomagnetic storm. Space Weather 17(7): https://doi.org/ 10.1029/2018SW002132.

Erickson GM, Spiro RW, Wolf RA. 1991. The physics of the Harang discontinuity. J Geophys Res Space Phys 96(A2): 1633-1645. https://doi.org/10.1029/90JA02344.

Figueiredo CAOB, Wrasse CM, Takahashi H, Otsuka Y, Shiokawa K, Barros D. 2017. Large-scale traveling ionospheric disturbances observed by GPS dTEC maps over North and South America on Saint Patrick's Day storm in 2015. J Geophys Res Space Phys 122: 4755-4763. https://doi.org/10.1002/2016JA023417.

Foster JC, Vo HB. 2002. Average characteristics and activity dependence of the subauroral polarization stream. $J$ Geophys Res Space Phys 107(A12): SIA 16-1-SIA 16-10. https://doi.org/ 10.1029/2002JA009409.

Galkin I, Reinisch B. 2008. The new ARTIST 5 for all digisondes. Ionosonde Network Advisory Group Bulletin 69: 1-8.

Gamache RR, Reinisch BW. 1990. Ionospheric Characteristics for Archiving at the World Data Centers. Tech. rep. Center for Atmospheric Research, University of Lowell.

Gonzales WD, Joselyn JA, Kamide Y, Kroehl HW, Rostoker G, Tsurutani BT, Vasyliunas VM. 1994. What is a geomagnetic storm? J Geophys Res 99(A4): 5771-5792. https://doi.org/ 10.1029/93JA02867.

Habarulema JB, Katamzi ZT, Yizengaw E, Yamazaki Y, Seemala G. 2016. Simultaneous storm time equatorward and poleward largescale TIDs on a global scale. Geophys Res Lett 43(13): 6678 6686. https://doi.org/10.1002/2016GL069740.

He M, Vogt J, Lühr H, Sorbalo E. 2014. Local time resolved dynamics of field-aligned currents and their response to solar wind variability. J Geophys Res Space Phys 119(7): 5305-5315. https://doi.org/10.1002/2014JA019776.

Heilig B, Lühr H. 2013. New plasmasphere model derived from CHAMP field-aligned current signatures. Ann Geophys 31(3): 529-539. https://doi.org/10.5194/angeo-31-529-2013.

Hocke K, Schlegel K. 1996. A review of atmospheric gravity waves and travelling ionospheric disturbances: 1982-1995. Ann Geophys 14: 917-940. https://doi.org/10.1007/s00585-996-0917-6.

Hoque MM, Jakowski N. 2012. Ionospheric propagation effects on GNSS signals and new correction approaches. In Jin S. (ed.), Global Navigation Satellite Systems, chap. 16, IntechOpen, Rijeka. https://doi.org/10.5772/30090.

Hunsucker RD. 1982. Atmospheric gravity waves generated in the high-latitude ionosphere: A review. Rev Geophys 20(2): 239-315. https://doi.org/10.1029/RG020i002p00293.

Jacobsen KS. 2014. The impact of different sampling rates and calculation time intervals on ROTI values. J Space Weather Space Clim 4(A33): 1-9. https://doi.org/10.1051/swsc/2014031.

Jacobsen KS, Dähnn M. 2014. Statistics of ionospheric disturbances and their correlation with GNSS positioning errors at high latitudes. J Space Weather Space Clim 4(A27): 1-10. https://doi. org/10.1051/swsc/2014024.

Jakowski N. 1996. TEC monitoring by using satellite positioning systems. In: Modern Ionospheric Science, 1st edn. Kohl H, Rüster R, Schlegel K (Eds.), European Geophysical Society. pp. 371-390.

Jin H, Zou S, Chen G, Yan C, Zhang S, Yang G. 2018. Formation and evolution of low-latitude $\mathrm{F}$ region field-aligned irregularities during the 7-8 September 2017 Storm: Hainan coherent scatter 
phased array radar and digisonde observations. Space Weather 16 (6): 648-659. https://doi.org/10.1029/2018SW001865.

Juan JM, Aragon-Angel A, Sanz J, González-Casado G, RoviraGarcia A. 2017. A method for scintillation characterization using geodetic receivers operating at $1 \mathrm{~Hz}$. J Geod 91: 1383-1397. https://doi.org/10.1007/s00190-017-1031-0.

Juan JM, Sanz J, Rovira-Garcia A, González-Casado G, Ibáñez D, Perez RO. 2018. AATR an ionospheric activity indicator specifically based on GNSS measurements. J Space Weather Space Clim 8(A14): 1-11. https://doi.org/10.1051/swsc/2017044.

Kelley MC. 2011. On the origin of mesoscale TIDs at midlatitudes. Ann Geophys 29(2): 361-366. https://doi.org/10.5194/angeo-29361-2011.

Kotake N, Otsuka Y, Ogawa T, Tsugawa T, Saito A. 2007. Statistical study of medium-scale traveling ionospheric disturances observed with the GPS networks in Southern California. Earth Planets Space 59: 95-102. https://doi.org/10.1186/BF03352681.

Kotake N, Otsuka Y, Tsugawa T, Ogawa T, Saito A. 2006. Climatological study of GPS total electron content variations caused by medium-scale traveling ionospheric disturbances. Geophys Res 111(A04): 306. https://doi.org/10.1029/2005JA011418.

Lühr H, Warnecke JF, Rother MKA. 1996. An algorithm for estimating field-aligned currents from single spacecraft magnetic field measurements: a diagnostic tool applied to Freja satellite data. IEEE Trans Geosci Remote Sens 34(6): 1369-1376. https://doi. org/10.1109/36.544560.

Liu J, Zhang D-H, Coster AJ, Zhang S-R, Ma G-Y, Hao Y-Q, Xiao Z. 2019. A case study of the large-scale traveling ionospheric disturbances in the eastern Asian sector during the $2015 \mathrm{St}$. Patrick's Day geomagnetic storm. Ann Geophys 37: 673-687. https://doi.org/10.5194/angeo-37-673-2019.

Mavromichalaki H, Gerontidou M, Paschalis P, Paouris E, Tezari A, Sgouropoulos C, Crosby N, Dierckxsens M. 2018. Real-time detection of the ground level enhancement on 10 September 2017 by A.Ne.Mo.S.: System report. Space Weather 16(11): 1797-1805. https://doi.org/10.1029/2018SW001992.

Mayer C, Belabbas B, Jakowski N, Meurer M. 2009. Ionosphere Threat Space Model Assessment for GBAS. In Proceedings of the 22nd International Technical Meeting of the Satellite Division of The Institute of Navigation, 1091-1099. ION GNSS+.

Mayer C, Jakowski N, Borries C, Pannowitsch T, Belabbas B. 2008. Extreme ionospheric conditions over Europe observed during the last solar cycle, In: Paper presented at 4th ESA Workshop on Satellite Navigation User Equipment Technologies, ESTEC, Noordwijk, Netherlands, 10-12 Dec.

Mendillo M. 2006. Storms in the ionosphere: Patterns and processes for total electron content. Rev Geophys 44(4): 1-47. https://doi. org/10.1029/2005RG000193.

Mishev AL, Usoskin IG. 2018. Assessment of the radiation environment at commercial jet-flight altitudes during GLE 72 on 10 September 2017 using neutron monitor data. Space Weather 16 (12): 1921-1929. https://doi.org/10.1029/2018SW001946.

Mosna Z, Kouba D, Knizova PK, Buresova D, Chum J, Sindelarova T, Urbar J, Boska J, Saxonbergova-Jankovicova D. 2020. Ionospheric storm of September 2017 observed at ionospheric station Pruhonice, the Czech Republic. Adv Space Res 65(1): 115-128. https://doi.org/ 10.1016/j.asr.2019.09.024.

Obana Y, Maruyama N, Shinbori A, Hashimoto KK, Fedrizzi M, et al. 2019. Response of the ionosphere-plasmasphere coupling to the September 2017 storm: What erodes the plasmasphere so severely? Space Weather 17(6): 861-876. https://doi.org/10.1029/ 2019SW002168.
Otsuka Y, Suzuki K, Nakagawa S, Nishioka M, Shiokawa K, Tsugawa T. 2013. GPS observations of medium-scale traveling ionospheric disturbances over Europe. Ann Geophys 31: 163-172. 10.5194/angeo-31-163-2013.

Paznukhov VV, Altadill D, Reinisch BW. 2009. Experimental evidence for the role of the neutral wind in the development of ionospheric storms in midlatitudes. J Geophys Res 114(A12319): 1-13. https://doi.org/10.1029/2009JA014479.

Pi X, Mannucci AJ, Lindqwister UJ, Ho CM. 1997. Monitoring of global ionospheric irregularities using the Worldwide GPS Network. Geophys Res Lett 24(18): 2283-2286. https://doi.org/ 10.1029/97GL02273.

Piggott W, Rawer K. 1972. U.R.S.I. Handbook of Ionogram Interpretation and Reduction. Rep. UAG-23. WDC-A for STP, 2nd edn. NOAA, Boulder, Colorado.

Pokhotelov D, Mitchell CN, Spencer PSJ, Hairston MR, Heelis RA. 2008. Ionospheric storm time dynamics as seen by GPS tomography and in situ spacecraft observations. J Geophys Res 113 (A00A16): 1-7. https://doi.org/10.1029/2008JA013109.

Pradipta R, Doherty PH. 2015. Assessing the occurrence pattern of large ionospheric TEC gradients over the Brazilian airspace. Navigation: Journal of The Institute of Navigation 63(3): 335-343. https://doi.org/10.1002/navi.141.

Prölss GW. 2006. Ionospheric F-region Storms: Unsolved Problems. In . Characterising the Ionosphere, Meeting Proceedings RTOMP-IST-056, 10-1 - 10-20.

Pulkkinen A, Amm O, Viljanen A, BEAR Working Group. 2003. Ionospheric equivalent current distributions determined with the method of spherical elementary current systems. J Geophys Res Space Phys 108(A2): 1053. https://doi.org/10.1029/2001JA005085.

Redmon RJ, Denig WF, Kilcommons LM, Knipp DJ. 2017. New DMSP database of precipitating auroral electrons and ions. $J$ Geophys Res Space Phys 122(8): 9056-9067. https://doi.org/ 10.1002/2016JA023342.

Reinisch B, Galkin I, Belehaki A, Paznukhov V, Huang X, et al. 2018. Pilot ionosonde network for identification of traveling ionospheric disturbances. Radio Sci 53(3): 365-378. https://doi. org/10.1002/2017RS006263.

Reinisch BW, Galkin LA. 2011. Global Ionospheric Radio Observatory (GIRO). Earth Planets Space 63: 377-381. https://doi.org/ 10.5047/eps.2011.03.001.

Richmond AD. 1995. Ionospheric electrodynamics using magnetic apex coordinates. J Geomag Geoelectr 47(2): 191-212. https://doi. org/10.5636/jgg.47.191.

Ritter P, Lühr H, Rauberg J. 2013. Determining field-aligned currents with the Swarm constellation mission. Earth Planets Space 65(9): 1285-1294. https://doi.org/10.5047/eps.2013.09.006.

Sato H, Jakowski N, Berdermann J, Jiricka K, Heßelbarth A, Banyś D, Wilken V. 2019. Solar radio burst events on 6 September 2017 and its impact on GNSS Signal Frequencies. Space Weather 17(6): 816-826. https://doi.org/10.1029/2019SW002198.

Shimeis A, Borries C, Amory-Mazaudier C, Fleury R, Mahrous A, Hassan A, Nawar S. 2015. TEC variations along an East EuroAfrican chain during 5th April 2010 geomagnetic storm. Adv Space Res 55(9): 2239-2247. https://doi.org/10.1016/j.asr.2015.01.005.

Shiokawa K, Otsuka Y, Ogawa T. 2009. Propagation characteristics of nighttime mesospheric and thermospheric waves observed by optical mesosphere thermosphere imagers at middle and low latitudes. Earth Planets Space 61: 479-491. https://doi.org/ 10.1186/BF03353165.

Tsugawa T, Saito A, Otsuka Y. 2004. A statistical study of largescale traveling ionospheric disturbances using the GPS network in 
Japan. J Geophys Res Space Phys 109(A6): 1-11. https://doi.org/ 10.1029/2003JA010302.

Wilder FD, Crowley G, Anderson BJ, Richmond AD. 2012. Intense dayside Joule heating during the 5 April 2010 geomagnetic storm recovery phase observed by AMIE and AMPERE. $J$ Geophys Res Space Phys 117(A5): A05,207. https://doi.org/10.1029/ 2011JA017262.

Xiong C, Lühr H, Wang H, Johnsen MG. 2014. Determining the boundaries of the auroral oval from CHAMP field-aligned current signatures - Part 1. Ann Geophys 32(6): 609-622. https://doi.org/ 10.5194/angeo-32-609-2014.

Yamauchi M, Sergienko T, Enell C-F, Schillings A, Slapak R, Johnsen MG, Tjulin A, Nilsson H. 2018. Ionospheric response observed by EISCAT during the 6-8 September 2017 space weather event: overview. Space Weather 16(9): 1437-1450. https://doi.org/10.1029/2018SW001937.

Zakharenkova I, Astafyeva E, Cherniak I. 2016. GPS \& GLONASS observations of large-scale traveling ionospheric disturbances during the 2015 St. Patrick's Day storm. J Geophys Res Space Phys 121 (12): 12138-12156. https://doi.org/10.1002/2016JA023332.

Zhang S-R, Coster AJ, Erickson PJ, Goncharenko LP, Rideout W, Vierinen J. 2019. Traveling Ionospheric Disturbances and Ionospheric Perturbations Associated with Solar flares in September 2017. J Geophys Res Space Phys 124: 5894-5917. https://doi.org/ 10.1029/2019JA026585.

Cite this article as: Ferreira AA, Borries C, Xiong C, Borges RA, Mielich J, et al. 2020. Identification of potential precursors for the occurrence of Large-Scale Traveling Ionospheric Disturbances in a case study during September 2017. J. Space Weather Space Clim. 10, 32. 